\title{
An advanced evaluation of spouted beds scale-up for coating TRISO nuclear fuel particles using radioactive particle tracking (RPT)
}

\author{
Neven Ali ${ }^{\mathrm{a}}$, Thaar Al-Juwaya ${ }^{\mathrm{a}}$, Muthanna Al-Dahhan ${ }^{\mathrm{ab} *}$ \\ ${ }^{\mathrm{a} N u c l e a r}$ Engineering, \\ ${ }^{\mathrm{b}}$ Chemical and Biochemical Engineering, \\ Missouri University of Science and Technology (Missouri S\&T) - Rolla \\ Rolla, MO 65409
}

\begin{abstract}
A set of dimensionless groups has been proposed in the literature by He et al. [He Y. L., Lim C. J., Grace J. R., Scale-up studies of spouted beds, Chemical Engineering Science, 52 (2), 329$339,1997]$ to scale-up gas-solid spouted beds while maintaining their hydrodynamics similarity. The literature reported studies do not provide conclusive assessments about this methodology. Therefore, in this work, we have applied an advanced non-invasive radioactive particle tracking (RPT) technique for the first time to evaluate such scale-up methodology by measuring the local solids velocity, normal and shear stresses and the turbulent kinetic energy. The axial and azimuthal averaged radial profiles of solids velocity, normal stresses, shear stresses, and turbulent kinetic energy illustrate that the similarity of the hydrodynamics has not been attained when the proposed set of dimensionless groups has been matched using two sizes of spouted beds of $0.076 \mathrm{~m}$ and $0.152 \mathrm{~m}$ and sets of operating conditions. The conclusion is consistent with the recent reported findings by measuring cross sectional distribution and radial profiles of solids and gas holdups along the bed height using gamma-ray computed tomography and by the limited point measurements of solids velocity and holdup using optical fiber probe. It is clear that local measurements of hydrodynamic parameters are essential for detailed assessment of scale-up methodologies. The presented results of our work in terms of the components profiles of the particles radial velocities and turbulent parameters are also valuable for benchmarking computational fluid dynamics codes and models.

*Corresponding author:

Tel.: +1 573341 7518; fax: +1 5733414377 .

E-mail addresses: aldahhanm@mst.edu
\end{abstract}

Keywords Scale-up, Spouted beds, TRISO, Radioactive Particle Tracking (RPT), 3-D velocity field, turbulence. 


\section{Introduction}

The fossil fuels (oil, coal and natural gas) are becoming increasingly depleted and will not satisfy future needs for energy [1]. Therefore, alternative energy resources have been sought. These alternatives include nuclear energy (particularly the $4^{\text {th }}$ generation nuclear energy), bioenergy (biomass gasification), and other renewable and alternative resources. The Very HighTemperature Reactors (VHTRs) are the most efficient of the fourth generation of nuclear reactors to meet energy demands for the $21^{\text {st }}$ century $[\underline{2}, \underline{3}]$. Passive safety is one of the most important features that characterize these reactors. The performance and the safety of the VHTRs depend highly on the quality of the TRISO (Tristructural-isotropic) fuel coated particles, and hence the fuel-coating technology and the related processes. In the coating process, the fuel kernel $\left(\mathrm{UO}_{2}\right.$ or $\left.\mathrm{PU}_{2}\right)$ is coated with four layers consisting of a porous buffer pyrolytic carbon layer (buffer PyC), an inner dense pyrolytic carbon layer (IPyC), a silicon carbide layer (SiC) and an outer dense pyrocarbon layer (OPyC) [4]. The technique used for coating the TRISO fuel particles is a gas-solid spouted bed via chemical vapor deposition (CVD) method. The TRISO fuel coating process is very delicate and must meet certain production requirements to be accepted. The level of defective coated particles is essentially zero, which is a challenge that requires a well understanding of the effects of design and operating variables on the performance of the gas-solid spouted bed coaters. The quality of the TRISO fuel, i.e. whether particles produced are uniformly or non-uniformly coated, is strongly impacted by the hydrodynamics of the gas-solid spouted bed, the solids flow field, and the flow regime characteristics [3, $\underline{5-8]}$. Accordingly, fundamental understanding of the underlying phenomena of the gas-solid spouted bed TRISO fuel particles coater using advanced measurement and diagnostic techniques is 
essential. This understanding will significantly help in the development of reliable and safe scale-up methodology and design, and ensure desired performance and operation of spouted bed TRISO fuel coaters.

In spouted beds, gas travelling at a high velocity through the inlet nozzle at the conical base of the spouted bed. This high velocity creates a jet in the spout region that picks up particles along the bed and carries them to the top of the bed where the particles create a fountain and disengage from the gas phase to fall down to the annular region. This particle movement follows a pathway of continuous circulation. Hence, the spouted bed usually contains three distinct regions as illustrated in Fig. 1; the central spout, the annulus, and the fountain regions. The particle concentration differs from region to region. In the central spout region, solid particles are pulled from the annulus region, carried through the spout by the gas to the fountain region. In the annulus region, the particles move downward as packed bed. Unsurprisingly, this is also the region with the maximum particles concentration. At the top of the bed, the particles form a fountain, where the particles and the gas phase disengage from each other. With no gas phase to hold them, the particles then fall downwards into the annulus region. Based on the flow structure, spouted beds are great candidates and well-suited to handle heavy, coarse, sticky, and/or irregularly shaped solids through cyclic flow patterns that are encountered in granulation, coating, gasification, and drying processes $[\underline{9}, \underline{10}]$. It is clear that such a flow pattern leads to complex hydrodynamics, recirculation flow, and gas-particle interactions. The key hydrodynamics of these contactors are solids flow field, solids circulation, solids velocity and turbulence parameters, gas dispersion, gas holdup radial profiles and cross-sectional distributions, and flow regime characteristics. Unfortunately, there is a lack of engineering and scientific knowledge within literature about spouted beds and their hydrodynamics [11, 12]. 
Recently, Ali et al. [13] studied the local solids and gas holdup distributions along the bed height using gamma-ray computed tomography (CT) technique which measures time averaged crosssectional distribution of phases densities and hence holdups. Also, Aradhya [14] investigated the local solids holdup and velocity in spouted beds using sophisticated and newly developed optical fiber probes which measure the point measurements of both solids velocity and solids concentrations (holdups with a proper calibration). These studies represent important steps towards increased understandings and ability to evaluate the literature reporting scale-up methodology of matching set of dimensionless groups.

Due to the complex hydrodynamic nature of gas-solid spouted beds, their scale-up, design, and performance have not been well-understood. In the literature, He et al. [15] proposed the following set of dimensionless groups to be matched in order to maintain hydrodynamics similarity of gas-solid spouted beds:

$$
\left\{\begin{array}{l}
\frac{g d_{p}}{U^{2}}, \frac{\rho_{s} d_{p} U}{\mu}, \frac{\rho_{f}}{\rho_{s}}, \frac{H}{d_{p}}, \frac{D_{c}}{d_{p}}, \phi_{s}, \varphi, \varepsilon_{o}, \\
\text { Dimensionless particle size distribution and dimensionless bed geometry. }
\end{array}\right.
$$

Where, $g d_{p} / U^{2}$ is Froude number, $\rho_{s} d_{p} U / \mu$ is Reynolds number, $\rho_{f} / \rho_{s}$ is ratio of fluid density to particle density, $H / d_{p}$ is ratio of bed height to particle diameter, $D_{c} / d_{p}$ is ratio of column diameter to particle diameter, $\phi_{s}$ is sphericity of particles, $\varphi$ is inertial friction angle of particle, ${ }^{\circ}$, and $\varepsilon_{O}$ is loose packed voidage. He et al. [15] extrapolated upon the scaling of dimensionless groups proposed by Glicksman [16] for gas-solid fluidized beds, so that they could be implemented on gas-solid spouted beds despite their hydrodynamic differences. He et al. [15] measured global parameters in order to claim the validity of such a methodology. Aradhya [14] demonstrated the dissimilarity using limited local point measurements of solids velocity and 
holdup by implementing an optical fiber probe when the proposed dimensionless groups of [15] were matched. Recently, Ali et al. [13] used gamma-ray computed tomography (CT) to assess such [15] scale-up methodology and also found that the similarity of solids and gas holdups cross-sectional distribution and their radial profiles along the bed height was not achieved by matching the proposed dimensionless groups. Following the work of [15], studies have been conducted in the literature to expand upon the dimensionless-group-based scale-up approach of spouted beds by adding the restitution coefficient $\left(e_{s s}\right)$ of particles to the set of dimensionless groups proposed by [15], [17, 18]. Also, further expansion was done by adding both the restitution coefficient and friction of the particles [19]. Rojas [20] studied different sizes of shallow spouted beds and different conditions without addressing the scale-up issue. However, [20] developed empirical correlations using various dimensionless groups to estimate various global parameters. Most of these dimensionless groups are represented by the set proposed by [15].

In all the studies mentioned above, the key local hydrodynamic parameters, of solids velocity and turbulent parameters (normal stresses, shear stresses, turbulent kinetics energy) have not yet been measured to assess, in detail, the scale-up methodology based on matching dimensionless groups of [15]. Without performing such evaluations, the comprehensive assessment of such a scale-up methodology will remain uncertain. As outlined above, the dimensionless groups proposed by [15] represent the foundation and basic groups for the scale-up methodology of gassolid spouted beds based on matching dimensionless groups. This set of dimensionless groups has not yet been evaluated by measurement of the local solids velocity and turbulent parameters. With these in mind, the dimensionless groups and the work of [15] represent the basis of this work when it comes to assessing the approach for matching dimensionless groups to scale-up 
gas-solid spouted beds. Accordingly, our study addresses the evaluation of such scale up methodology by implementing the radioactive particle tracking (RPT) technique to locally measure the three-dimensional solids velocity components and the turbulent parameters (including normal stresses, shear stresses, turbulent kinetic energy) over the height section of the measurements.

\section{Experimental work}

\subsection{Spouted beds setup}

The experimental works were carried out in two conical base spouted bed columns made of Plexiglas. They are of different diameters; one column has a diameter of $0.076 \mathrm{~m}$ and the other, $0.152 \mathrm{~m}$. The schematic diagrams of the two spouted beds used are shown in Fig. 2. Both columns were designed to be geometrically similar with a height of $1.14 \mathrm{~m}$ and a conical base angle of 60-degrees. The two columns were designed without any ports or connections on their wall in order to eliminate the possibility of any non-symmetric problems, which complicates the RPT reconstructions process. Each unit consists of a one-piece column attached to a conical base. At the bottom of the conical base, there is a gas distributor made of stainless steel placed to allow the flow of gases to form a jet inside the column. The diameter of the inlet orifice is 9.5 $\mathrm{mm}$ for the $0.076 \mathrm{~m}$ spouted beds and $19.1 \mathrm{~mm}$ for the $0.152 \mathrm{~m}$ spouted beds. The gas used was dry compressed air supplied from an industrial compressor with capacity up to 735 CFM and 200 Psig. After the flow passes through the piping components of the compressor, the rate of the flow is regulated using a pressure regulator and rotameter setup consisting of two rotameters connected in parallel to each other. The gas flow rates were measured using the two rotameters and gas flow was introduced into the spouted beds through the inlet orifice (gas distributor). To 
maintain stable spouting in spouted beds, the conditions of the experiments used in [13] were followed.

\subsection{Experimental conditions.}

Three different conditions from the study of He et al. [15] for the scale-up of spouted beds with matched and mismatched scaling groups, were selected in this work and are similar to conditions used by Ali et al. [13]. The experimental conditions, including the properties of the particles used and the operating conditions, are listed in Table 1. Case A and Case B were designed to achieve matching dimensionless groups to examine the validity of spouted bed scaling groups. The dimensionless groups of Case B were matched as closely as possible to those of Case A. Then, both Cases were deemed as having matching dimensionless groups. Case A was proposed as the reference Case. Case C (prototype Case) was conducted in order to examine the influence of mismatched scaling groups. The design of Case $\mathrm{C}$ was also proposed for the study of common unsuitable scale-up criteria when only the bed dimensions are varied to achieve geometrical similarity; while others scaling groups were not matched. The initial bed height $(H)$ and the inner column diameter $\left(D_{c}\right)$ in Case $\mathrm{C}$ were made to be $0.16 \mathrm{~m}$ and $0.076 \mathrm{~m}$, respectively, to achieve similarity with Case A with regards to only bed dimensionless groups. The scaling groups $H / D_{c}, D_{c} / D_{i}$, and $D_{c} / d_{p}$ had values equal to those of Case A. However, two important groups were not matched in Case $\mathrm{C}$ - Reynolds number and the Froude number. Reynolds number for Cases A and C were 157 and 54, respectively, and the Froude number for Cases A and $\mathrm{C}$ were 54.5 and 51.2, respectively. Dissimilar to Case B, some parameters were not taken into account for Case $\mathrm{C}$, so that we were able to get matching dimensionless groups. For example, the gas in Case $\mathrm{C}$ was at atmospheric pressure, while in Case $\mathrm{B}$, the bed pressure was 
increased to $312 \mathrm{kpa}$. In addition, the type of particles and their densities were not changed in

Case C from those of Case A. Both used glass beads particles $\left(\rho_{s}=2400 \mathrm{~kg} / \mathrm{m}^{3}\right)$. In Case B, steel particles were used to match the scaling groups. Subsequently, Cases A and B will be termed as having matching dimensionless groups and Cases $\mathrm{A}$ and $\mathrm{C}$ will be termed as having mismatched dimensionless groups.

\subsection{The Radioactive Particle Tracking (RPT) Technique.}

The Radioactive Particle Tracking (RPT) technique is a non-invasive technique used to track single radioactive particles that match the density and size of those in the bed's solid phase. This is done by measuring emitted gamma-ray intensities. The RPT technique has been successfully applied to measure and visualize 3D flow fields and turbulence parameters in different multiphase flow systems $[\underline{11}, \underline{12}, \underline{21-33}]$. In this work, RPT has been implemented to assess in detail, for the first time, the scale-up study of spouted beds based on the matching of dimensionless groups [15]. In addition, implementing the RPT technique on gas-solid spouted beds will significantly advance the fundamental understanding and knowledge of the complex turbulence patterns of spouted beds and provide reliable data on the turbulent characteristics, regarding the flow, in a non-invasive manner. Increased knowledge on this topic will help to evaluate and validate CFD and related models and closures.

In the RPT experiments, the gamma-rays emitted by the tracer particle were collected using twenty-eight high-resolution $(5.08 \mathrm{~cm} \times 5.08 \mathrm{~cm}) \mathrm{NaI}(\mathrm{TI})$ detectors arranged strategically around the spouted bed, as shown in Fig. 3. The 28 detectors are located at 14 axial levels with two detectors in each level facing one another (180-degree angle to each other). The detectors 
were mounted on movable horizontal aluminum structures that are in turn held by four vertical Unistrut bars equally distanced from the column and separated at 90-degree intervals around the column. Each Unistrut supporter had seven detectors placed at different axial levels. The detectors were positioned vertically with respect to the expected bed dynamic. In addition, each detector was radially arranged $12.7 \mathrm{~cm}$ from the symmetrical axis of the column. This location is selected to avoid saturation problem of the detectors when the tracer particle is very close to the wall of the column [34]. The detectors are horizontally level and aligned in both axial and azimuthal directions using a leveling device and twin laser-equipped aluminum fake detectors that faced each other.

The tracer particle for each RPT experiment was made in the case it should be as close as possible to size, density, and shape of the tagged solid phase. The tracer particle is embedded with Co-60 $\left(d_{p}=600 \mu \mathrm{m}\right)$ with an activity of about $500 \mu \mathrm{ci}$ (microcurie) at the time of the experiments. The Co-60 is commonly used because of its small scatter interference of signals due to high-energy peaks (1.18 MeV and $1.34 \mathrm{MeV})$ which are close to each other and we measure them by our data acquisition system. In addition to that, the high gamma energy of cobalt-60 allows it to penetrate the dense zone (the annulus) and register at the detector when the particle is in the spout. Co-60 has half-life of 5.28 year, which allows us to use it for longer time. The RPT experiment consists of two steps: an RPT calibration process and an RPT actual experimental process.

In order to estimate the position of the tracer particle, calibration was performed before the actual RPT experiment by placing the tracer particle at various known locations. This yielded a calibration map relating counts and particle positions for each detector. In the calibration 
process, a fully automatic calibration device was used to provide highly accurate RPT measurements. This device can automatically move in all directions to visit hundreds or thousands of known locations inside the spouted bed column. The movement of this device was controlled by a data acquisition system, and locations were detected by a tracer-particle-tipped calibration rod. The generated calibration maps of distance counts for all detectors will be used as part of in-house developed algorithms and programs for reconstructing the positions of the tracer particle during the actual experiment.

The local statistical characteristics were assessed with approximately two million data points obtained from fourteen hours of particle tracking in $0.152 \mathrm{~m}$ spouted beds, and one million data points obtained from six hours of particle tracking in $0.076 \mathrm{~m}$ spouted beds. For both beds, the counting acquisition frequency was $50 \mathrm{~Hz}$. The 3D instantaneous particle positions were reconstructed from the count rate of the tracer particle using a cross-correlation-based position algorithm coupled with a semi-empirical model in order to provide further calibration points. This method was based on relating tracer particle count rate to the positions of the particle. The cross-correlation-based position method was originally developed and used for the processing of RPT data on gas-solid risers [24]. The method was also used in our laboratory for a pebble bed reactor study [35]. For further details about the technique and algorithms used to reconstruct the particle positions, the reader can refer to recent works of our group [프, 36].

In order to obtain the time-averaged velocity and turbulence parameters, it is required to identify the initial particle coordinates in the spouted bed column. To accomplish this, cylindrical mesh compartments of equal volume were defined to represent the entire column of the spouted bed. Two important points were considered when determining the sampling compartments: the 
sufficient occurrences of the particle per compartment, and a good radial profile description for each bed height level. The sampling compartments were evaluated and the column was divided into 1127 and 735 compartments for $0.152 \mathrm{~m}$ and $0.076 \mathrm{~m}$ spouted beds, respectively. All the while, the eight radial points for the profile description were maintained.

Once the instantaneous positions of the tracer particle and its lagrangian trajectory were defined, the next step was to calculate the instantaneous particle velocity $(r, \theta$, and $z)$ and the turbulence parameters in each compartment. The distance traveled by the particle between two successive positions divided by the time interval needed to travel that distance, yielded its velocity.

$$
\left(\begin{array}{c}
u_{r} \\
u_{\theta} \\
u_{z}
\end{array}\right)=\frac{1}{T}\left(\begin{array}{c}
r_{i+1}-r_{i} \\
r_{m}\left(\theta_{i+1}-\theta_{i}\right) \\
z_{i+1}-z_{i}
\end{array}\right) \text { where }\left\{\begin{array}{c}
T=t_{i+1}+t_{i} \\
r_{m}=\left(r_{i+1}+r_{i}\right) / 2
\end{array}\right.
$$

Then, based on the ensembled particle total number of occurrences per compartment $\left(N_{v}\right)$, the time-averaged (mean) velocity fields in each compartments $(i, j, k)$ were calculated as follows:

$$
\bar{u}_{p(i, j, k)}=\frac{1}{N_{v}} \sum_{i=1}^{N_{v}} u_{p(i, j, k) i} \quad p=r, \theta, z
$$

For data presentation, the circular azimuthal averaging was performed for each $(\mathrm{r}, \mathrm{z})$ level to calculate the azimuthally-averaged velocity $\left(\bar{u}_{p(i, j, k)}\right)$ for the axial and radial components, where $N_{\theta}$ is the number of compartments in the azimuthal direction. As a result, eight positions of the profile description were obtained along the radial direction for each $(\mathrm{z})$ level:

$$
\bar{u}_{(i, k)}=\frac{1}{N_{\theta} \tilde{N}_{v(i, k)}}=\sum_{j=1}^{N_{\theta}} \bar{u}_{(i, j, k)} N_{v(i, j, k)}
$$




$$
\tilde{N}_{v(i, k)}=\frac{1}{N_{\theta}} \sum_{j=1}^{N_{\theta}} N_{(i, j, k)}
$$

In this equation, $\widetilde{N}_{v(i, k)}$ is the average number of velocity occurrences for a given twodimensional compartment $(i, k)$. Hence, the fluctuation velocity $(u)$ was conventionally calculated by subtracting the mean velocity $(\bar{u})$ from the instantaneous velocities ensembled $(u)$ as follows:

$$
u_{p(i, j, k)}^{\prime}=u_{p(i, j, k)}-\bar{u}_{p(i, j, k)}
$$

Once the fluctuation velocities were obtained, the turbulent stresses, and turbulent kinetic energy per unit mass can be calculated as follows:

$$
\begin{gathered}
\tau_{p q}=\overline{u_{p(i, j, k)}^{\prime} u_{q(i, j, k)}^{\prime}} \quad p, q=r, \theta, z \\
T K E=\frac{1}{2}\left(\tau_{r r}+\tau_{\theta \theta}+\tau_{z z}\right)
\end{gathered}
$$




\section{Results and discussion}

As mentioned earlier, three sets of experimental conditions, in two differently-sized spouted beds, were used to evaluate the dimensionless relationships of [15] so that hydrodynamic similarity is maintained in the spouted beds. The experimental conditions were originally selected to capture matched and mismatched dimensionless groups between the conditions as outlined in Table 1. In this section, Cases A (0.152 m diameter bed) and B (0.076 m diameter bed) were designated to have matching dimensionless groups, and Cases A and C (0.076 m diameter bed) were designated to have mismatched dimensionless groups. Case A represents the reference conditions.

\subsection{Radial Profiles of the Averaged Particles Velocity}

In this section, the results of the azimuthally and axially averaged axial and radial particle velocities radial profiles are presented and discussed. Due to the insignificance of the averaged azimuthal (angular) particle velocity value, which is smaller than the axial and radial particle velocities, the averaged azimuthal particle velocity is not presented here. 


\subsubsection{Radial Profiles of the Averaged Axial Particles Velocity}

In spouted beds, three distinct regions exist and each one has a specific flow behavior. The solids are carried up by the gas phase in the spout region, which functions as a gas-solid riser, until it reaches the top of the bed surface. Here, the solids are disengaged from the gas phase and are in the fountain region. The solids fall down freely, due to gravity, onto the annulus region. During such solid circulation, the three known regions of spouted beds are created; they include the spout in the center of the column, the annulus surrounding the spout, and the fountain on the top of the spout-annulus regions. Fig. 4 shows the azimuthally and axially averaged profiles of the averaged axial particle velocity for the reference Case (Case A) and the conditions of matched (Case B) and mismatched (Case C) dimensionless groups in $0.152 \mathrm{~m}$ and $0.076 \mathrm{~m}$ spouted beds. The results show the magnitude and pattern of the averaged axial velocity of the particles in each region of the spouted beds. In the spout, the particles move upwards (i.e. $U_{z}>0$ ) with a higher axial velocity at the center zone of the spout, where the particles are carried up by the gas phase. The velocity of the solids decrease radially out from the axis (i.e. center of the spout) toward the spout-annulus interface. This is in agreement with the results obtained by the CT technique [13] where weak divergence in the solids holdup profile is observed at the spoutannulus interface. When the particles reach the fountain, the axial velocity is at maximum near the axis but becomes negative (i.e. downward, $\mathrm{U}_{\mathrm{Z}}<0$ ) as particles fall in the outer region of the fountain. For matched (Case B) and mismatched (Case C) conditions, deviations from the averaged axial velocity profile of the reference Case (Case A), are generally apparent in the spout and fountain regions. In the spout region, the average profile deviation percentage from

that of the reference Case (Case A) is found to be $18.91 \%$ and $45.24 \%$ for the conditions of matched (Case B) and mismatched (Case C) dimensionless groups, respectively. In the annulus, 
the axial particle velocity observed is low and negative for all the Cases. Also, the deviations between the profiles are relatively small because the particles move downwards slowly in the loosely moving packed bed. This is in agreement with the results obtained using the CT technique [13], where the solids-holdup profiles in this region remain similar and unchanged between the Cases. In the fountain, the average profile deviation percentage from that of Case A, is $47.48 \%$ and $46.54 \%$ for the conditions of matched (Case B) and mismatched (Case C) dimensionless groups, respectively. In Case B the pressure (312 Kpa) is higher than that of Case C (101 Kpa) while the superficial velocities $(0.75$ and $0.74 \mathrm{~m} / \mathrm{s})$ and particles diameters (1.09 $\mathrm{mm})$ are the same. This means that more mass flow rate of air is introduced into the spouted bed of Case B. Hence, Reynolds number $\left(R e=\rho_{s} d_{p} U / \mu\right)$ is larger for Case B (168) than that of Case C (54) which impart larger momentum on and energy transfer to the steel particles of Case B making their local velocity higher than that of Case C. In addition, our findings showed that the solid particles velocity in the spout region reduces with the height of the bed. This is due to insertion of solid from the annulus region to the spout region along the height of the bed. This is in agreement with our gamma-ray computed tomography (CT) technique results [13]. Which showed higher solids holdups in the spout region at higher bed levels. More solids to be carried by the gas phase reduces the particles velocity where the transferred energy and the imparted momentum on the particles are dissipated to more particles at the upper levels compared to the lower levels of the spout region. The particles velocity in the spout region should be higher than that in the fountain region since the fountain region is a disengagement region between the solids particles and the up flow of the gas phase. The mass velocity of the gas is lower in the fountain region as compared to the spout region due to larger cross-sectional area of the fountain region. Hence, the momentum that is imparted on the particles is lower in the fountain region making the 
particles velocity lower in the fountain region as compared to those in the spout region, which facilitate the disengagement of the particles from the gas phase, and hence they fall down back to the annulus region.

The above results represent the actual velocity values of the solids, which normally differ with increases to the bed size or modifications to operating conditions for similar bed geometries. Therefore, to assess for hydrodynamic similarity, these values should be presented in the form of dimensionless values using a known or measurable parameter. In this case, the minimum spouting velocity $\left(\mathrm{U}_{\mathrm{ms}}\right)$, which can be estimated with an acceptable level of fidelity [37], has been selected to convert the actual velocity values of local solids, into dimensionless values. This can facilitate the attainment of the similarity for scale-up. In this case the actual solids velocities at the scaling-up conditions can be estimated by using the dimensionless local solids velocities of a reference Case-but only if the minimum spouting velocity of those scaling-up conditions can be estimated. Therefore, to assess the comparison between the Cases (Cases A and B and Cases A and C) for matching and mismatching dimensionless group conditions, the profiles of the Cases' axial particle velocities are non-dimensionalized by dividing them by the minimum spouting velocity $\left(\mathrm{U}_{\mathrm{ms}}\right)$. Minimum spouting velocity $\left(\mathrm{U}_{\mathrm{ms}}\right)$ is defined as the minimum superficial gas velocity that is required to obtain the spouting state in spouted beds; below this velocity, solids circulation is absent and all three spouted bed regions are not entirely created. In this work, the minimum spouting velocities $\left(\mathrm{U}_{\mathrm{ms}}\right)$ for the conditions in Table 1 were measured by increasing the superficial gas velocity slowly from the state of fixed bed to the onset of external spouting. The measured values of minimum spouting velocity $\left(\mathrm{U}_{\mathrm{ms}}\right)$ are listed in Table 1. 
Accordingly, the dimensionless axial particle velocity profiles for the conditions of the reference Case (Case A), and cases with matched Case (B) and mismatched Case (C) dimensionless groups are shown in Fig. 5. Deviation is observed between the profiles of these Cases in the spout and the fountain regions. It has been noted that the difference between the profiles have increased when compared to those of the actual axial particle velocities illustrated in Fig. 4. In the spout, the average profile deviation percentage of Cases A and B is $33.97 \%$. Near the axis of the spout, $(\mathrm{r} / \mathrm{R}=0.0625)$ the deviation is $37.15 \%$. Near the spout-annulus interface $(\mathrm{r} / \mathrm{R}=0.427)$, it is $32.36 \%$. In the fountain region, the average percentage deviation is also augmented and has a value of $107.41 \%$. The most significant amount of deviation is in the outer region of the fountain where the average value is $169.78 \%$. In the annulus region, the deviation between the profiles remained small and insignificant.

The dimensionless axial particle velocities for the conditions of mismatched (Case C) dimensionless groups are also shown in Fig. 5. The profiles of Case A and Case C spouted beds deviate from each other noticeably in the spout and fountain regions. The deviation is larger near the center of the spout and decreases as the radial distance from the axis increases up to the spout-annulus interface, where the spout is confined by the annulus. Near the axis of the spout $(\mathrm{r} / \mathrm{R}=0.0625)$, the deviation is $49.38 \%$, and at the spout-annulus interface, it is $32.36 \%$. In the fountain region, the deviation increases and has an average value of $49.04 \%$. The results signify the failure of achieving sufficient hydrodynamics similarity between the cases by matching the dimensionless groups proposed [15]. 


\subsubsection{Radial Profiles of the Averaged Radial Particles Velocity}

The horizontal radial component of the particle velocity was measured using RPT for the conditions of matched and mismatched dimensionless groups shown in Table 1 . The azimuthally and axially averaged radial profiles of the radial particle velocities for the $0.152 \mathrm{~m}$ and the 0.076 $\mathrm{m}$ spouted beds are shown in Fig. 6. The magnitudes of the averaged radial particle velocities are small compared to the averaged axial particle velocity. This is because of the symmetrical gassolids flow within the axes of the spouted beds. The results show the variation in particle movement and depict the behavior of the averaged radial particle velocity in all the three regions (the spout, the annulus, and the fountain). In the spout region, the particle moves towards the axis (i.e. inward, $\mathrm{Ur}<0$ ) of the spout with the maximum negative value obtained from approximately the middle between the center of the spout and the spout-annulus interface $(\mathrm{r} / \mathrm{R}=0.2)$. After this point from the center, the averaged absolute radial particle velocity decreases until you reach the spout-annulus interface (becomes increasingly less negative in value). For both conditions, the most deviation observed from those of the reference Case (Case A), was in the spout and the fountain regions. In the spout region, the average profile deviation percentage was $45.88 \%$ and $54.4 \%$, respectively, for the conditions of matched and mismatched dimensionless groups. In the annulus region, the profiles are nearly flat. The radial particle velocity then changes into positive values (i.e. outward, $\mathrm{Ur}>0$ ) when the particles reach the fountain region. The profiles show a radial dispersion in the fountain due to scattering of the particles in the r-direction. The averaged profile deviation percentage is $42.41 \%$ and $50.76 \%$ for the conditions of matched and mismatched dimensionless groups, respectively.

Similar to the section discussing averaged axial particle velocity, the profiles of the averaged radial particle velocity were non-dimensionalized for both bed sizes by dividing by the minimum 
spouting velocity $\left(\mathrm{U}_{\mathrm{ms}}\right)$. Fig. 7 shows the deviation of dimensionless radial particle velocities for the conditions of matched and mismatched dimensionless groups. Deviation is witnessed once again between the profiles in the spout and fountain regions for the conditions of matched and mismatched dimensionless groups, from those of the reference Case (Case A). This indicates that matching the dimensionless groups in the scale-up cannot give good predications of radial particle velocities. The averaged profile deviation percentages are $62.84 \%$ and $55.31 \%$, respectively, for the conditions of matched and mismatched dimensionless groups. In the fountain, the deviation between dimensionless values of the Cases increased from that of the absolute values, and has an average value of $95.03 \%$ and $55.09 \%$, respectively, for the conditions of matched and mismatched dimensionless groups. The results signify that matching dimensionless groups between the two beds correspondingly, gives a large difference between the dimensionless averaged radial particle velocities in the spout region.

\subsection{Radial Profiles of the Averaged Particle Normal Stresses}

\subsubsection{Radial profiles of the Averaged Axial Particle Normal stresses}

Fig. 8 illustrates the radial profiles of the azimuthal and axial averaged normal stresses $\left(\tau_{\mathrm{zz}}\right)$

for the reference Case (Case A), the conditions of matched dimensionless groups (Case B), and the conditions of mismatched dimensionless groups (Case C) in $0.152 \mathrm{~m}$ and $0.076 \mathrm{~m}$ spouted beds, respectively. The results show the magnitude and the pattern of $\tau_{\mathrm{zz}}$ of the particles in each region of the spouted beds. In the spout, the magnitude of $\tau_{\mathrm{zz}}$ is much larger than in the other regions. The maximum value is detected in the center zone of the spout region. This is because the axial particle velocities and the related fluctuation velocities are also maximal in the central 
zone of the spout. Since the axial particle velocities and their fluctuations reduce radially outwards to the annulus zone, the same trend is found for the $\tau_{\mathrm{zz}}$. The $\tau_{\mathrm{zz}}$ for Case $\mathrm{A}$ is larger than that of Case B (matched dimensionless groups) and even greater than that of Case C (mismatched dimensionless groups). In the spout region, the absolute relative differences of the profiles, with respect to Case A, are $36.11 \%$ and $60.12 \%$ for Cases $\mathrm{B}$ and $\mathrm{C}$, respectively. The differences in percent among these Cases for $\tau_{\mathrm{zz}}$ are larger in the center zone of the spout and reduces outwards as you approach the annulus region. At the annulus region, due to the nature of the flow structure, the magnitudes of $\tau_{\mathrm{zz}}$ are much lower than those of the spout region $\left(\tau_{\mathrm{zz}}<500\right.$ 1000 As compared to $\tau_{\mathrm{zz}}$ of about 14000 in spout region); also, $\tau_{\mathrm{zz}}$ magnitudes are similar between cases. This is also due to the velocities of solids and the fact that their fluctuations are small. Remember that solids move downwards as a packed bed as discussed earlier (Fig. 1). At the fountain region, $\tau_{\mathrm{zz}}$ values are smaller near the bed axis and they increase towards a maxima at the zone of about $\mathrm{r} / \mathrm{R}=0.4$; and then they decrease towards the bed wall. This trend indicates that the axial particle velocity fluctuations in the central zone of the bed of the fountain are smaller, despite the fact that particle velocities at the fountain zone are larger. At the zone of about $\mathrm{r} / \mathrm{R}=0.4$ shown in Fig. 4 the axial particle velocities invert from positive (upward) to negative (downward) values. Therefore, the fluctuations of the axial velocities are larger in this zone of the bed. These fluctuations decrease towards the wall of the bed and hence, $\tau_{\mathrm{zz}}$ decreases. The same trend is found during the comparison between the Cases. The axial normal stress of Cases $\mathrm{A}$ and $\mathrm{B}$ deviate from each other by $27.32 \%$; the deviation of Cases $\mathrm{A}$ and $\mathrm{C}$ is more obvious, at about $65.52 \%$. It is clear that the local radial profiles of $\tau_{\mathrm{zz}}$ are different when the dimensionless groups are matched. The differences are even more pronounced for the conditions of mismatched dimensionless groups. When the magnitudes of $\tau_{\mathrm{zz}}$ are converted to dimensionless 
values with respect to the squared minimum spout velocity, the trend of differences remain the same and the magnitudes of the percentage differences get even larger, as demonstrated in Fig. 8. The average deviation between the profiles for matching dimensionless groups increases to $40.47 \%$ and $66.56 \%$, respectively, at the spout and the annulus regions. This further confirms that the list of dimensionless groups provided by [15] for attaining hydrodynamic similarity, is not adequate and that such scale-up methodology is further invalidated.

\subsubsection{Radial Profiles of the Averaged Radial particle Normal stresses}

Fig. 9 illustrates the magnitudes and radial profiles of the azimuthal and axial radial normal stresses $\left(\tau_{\mathrm{rr}}\right)$ for the reference Case (Case A), the conditions of matched dimensionless groups (Case B), and the conditions of mismatched dimensionless groups (Case C) in $0.152 \mathrm{~m}$ and 0.076 m spouted beds. It is obvious that the magnitudes of $\tau_{\mathrm{rr}}$ are much smaller than those of $\tau_{\mathrm{zz}}$ in the three studied regions of the spouted beds. In the spout and annulus regions, the $\tau_{\mathrm{rr}}$ values are comparable to those of $\tau_{\mathrm{zz}}$ in the annulus region. This is due to negligible velocity and its fluctuations in the radial direction. However, in the fountain region, due to the flow structure of the fountain and the freely falling particles, non-negligible particle radial velocities and their fluctuations exist. Hence, the magnitudes of $\tau_{\mathrm{rr}}$ are much larger than those in the spout and annulus regions. Similar to $\tau_{\mathrm{zz}}$ trends and profiles, there are $\tau_{\mathrm{rr}}$ maxima in the region between $\mathrm{r} / \mathrm{R}=0.4$ and $\mathrm{r} / \mathrm{R}=0.6$, which indicates that larger radial particle velocity fluctuations and magnitudes exist in this zone. This is consistent with the trend and profiles of the particle radial velocities shown in Fig. 6. When the magnitudes of $\tau_{\mathrm{rr}}$ are converted into dimensionless values with respect to the squared minimum spout velocity, the trend of differences remain the same. However, the magnitude percentage difference gets even larger, as demonstrated in Fig. 9. The 
dimensionless averaged radial normal stresses of Cases A and B deviate from each other by $53.6 \%$ and $51.8 \%$ at the spout and the annulus regions, respectively. This further confirms the lack of reproducibility regarding the dimensionless groups' approach of [15] for the scale-up of spouted beds for hydrodynamic similarity.

\subsubsection{Radial Profiles of the Averaged Azimuthal Particle Normal stresses}

The azimuthal and axial averaged azimuthal normal stresses' $\left(\tau_{\theta \theta}\right)$ radial profiles are illustrated in Fig. 10. Due to the flow nature in the spout and annulus regions, where the particles move downwards in the annulus region and move angularly as they enter into the spout region from the spout-annulus interface, the angular velocity fluctuations are higher than those for radial velocity components. Therefore, the magnitudes of the $\tau_{\theta \theta}$ in the spout and annulus regions are higher than those of the $\tau_{\mathrm{rr}}$, but in the spout region, they are smaller than those of the $\tau_{\mathrm{zz}}$. In the fountain region, due to the rotational nature of the fountain flow structure, the angular velocity fluctuations are also noticeable. Hence, the magnitudes of $\tau_{\theta \theta}$ are comparable to those in the spout region. However, the trend is different from those of $\tau_{\mathrm{rr}}$ and $\tau_{\mathrm{zz}}$, where maxima do not exist. The maximum values of the $\tau_{\theta \theta}$ are at the center zone of the spout region and they decrease as the annulus region is approached. However, in the fountain region, they decrease towards the wall, where the fluctuations in the angular direction and the magnitude of the angular velocity component get smaller. Also the values at the reference conditions are larger than those at the conditions with matching and mismatching dimensionless groups, which further confirm the non-validity of the proposed set of dimensionless groups [15]. When the magnitudes of $\tau_{\theta \theta}$ are converted into dimensionless values with respect to the minimum spout velocity, the average deviation in the spout between Cases A and B is 41.96\%; between Cases A and C, it is $64.93 \%$. 
This further confirms that the previously mentioned set of dimensionless groups that were proposed to be adequate for scale-up methodology and attaining hydrodynamic similarity, are further invalidated.

\subsection{Radial Profiles of the Averaged Particle Shear stresses}

Fig. 11 and Fig. 12 show the azimuthal and axial averaged shear stresses' radial profiles for the studied conditions mentioned above (Cases A, B, and C). In the spout region, $\tau_{\mathrm{rz}}$ radial profiles show maxima at the zone between the center of the spout and the spout-annulus interface $(\sim \mathrm{r} / \mathrm{R}=0.2)$. This trend reflects the magnitude of the fluctuations in the axial and radial components of the velocities; their multiplication gives the maximum value at $\sim \mathrm{r} / \mathrm{R}=0.2$. At about the spout-annulus interface, the $\tau_{\mathrm{rz}}$ values are negative from about $\mathrm{r} / \mathrm{R}=0.35$ to about $\mathrm{r} / \mathrm{R}=0.6$. In the annulus region, the values of $\tau_{\mathrm{rz}}$ are small compared to those of the spout region due to the nature of the annulus's flow structure. In the fountain region however, the maximum value occurs in the zone of about $\mathrm{r} / \mathrm{R}=0.7$. At both the center zone and the wall zone, the $\tau_{\mathrm{rz}}$ values are comparable for all the studied Cases. It is clear that there is a mismatch in the magnitudes of the $\tau_{\mathrm{rz}}$ between the reference conditions of Case A and the matching dimensionless groups conditions (Case B). The differences get larger between mismatching dimensionless groups (Case A compared with Case C). In addition, when $\tau_{\mathrm{rz}}$ values are converted into dimensionless values using the minimum spouting gas velocity, the differences in values still exist and get larger, as summarized in Table 2. This confirms that the dimensionless groups proposed by [15] are not adequate for scale-up and for hydrodynamic similarity. Furthermore, particle-particle interaction causes the fluctuations in the particles velocity in the spout and the fountain regions but it is not dominating over the fluid-particle interaction. Therefore, 
mentioning that the high-velocity fluctuation and high mean velocities are the reasons is like mentioning that the stresses are induced by the gas turbulence and the particle-particle interactions. In addition to that, fluctuations in the dilute regions (spout and fountain) and the dense region (annulus) are of different origins [11]. In the annulus, fluctuations are mainly connected to voidage in annulus, and particle-particle contacts and interaction forces. Therefore, fluctuating movement exist at the spout-annulus interface and in the annulus but cannot be higher than that obtained in the spout. In another word, the contribution of the axial component of particle velocity is very high on the fluctuation intensity of the particle. However, in the fountain region due to the reduction in the mass velocity of the gas phase and hence the momentum imparted on the particles because of larger cross-sectional area for the gas to flow makes the particles velocity lower as compared to the spout region. Also due to the disengagement of the particles and the gas in this region, the particles change direction of the flow from upward to downward forward the annulus region. These make the nature of the particles fluctuation different from that in the spout region, which make the stress profiles, and magnitude in the fountain region different from those in the spout region.

\subsection{Radial Profiles of the Averaged particles turbulent kinetic energy}

Fig. 13 demonstrates the turbulent kinetic energy in the three regions of the studied spouted beds for the conditions of Cases A, B, and C. The turbulent kinetic energies of the particles are larger in the center zone of the spout region for the Cases and reduces as the spout-annulus interface is approached. This trend is similar to the trends of the $\tau_{\mathrm{zz}}$ and $\tau_{\theta \theta}$, whose values are significant compared to $\tau_{\mathrm{rr}}$. At the annulus region, the turbulent kinetic energy levels off and the 
magnitudes are smaller than those of the spout region are. In the fountain region, the turbulent kinetic energy magnitudes are comparable to those of the spout region's center zone; the maximum value exists at the region between about $\mathrm{r} / \mathrm{R}=0.4$ to $\mathrm{r} / \mathrm{R}=0.5$. This is similar to the trends for $\tau_{\mathrm{zz}}$ and $\tau_{\mathrm{rr}}$, whose values are dominating the estimated values of turbulent kinetic energy. The radial profile values of the turbulent kinetic energies for Case A (reference conditions), noticeably differ from those of Case B, where the dimensionless groups of [15] are matched. When the dimensionless groups are not matched (Case C compared with Case A), the difference in values of the turbulent kinetic energy get larger. This means that more differences in dimensionless groups would lead to more differences in local hydrodynamic parameters. Similar findings related to the differences between Cases A, B, and C were obtained when the turbulent kinetic energy values are converted into dimensionless values. This further confirms the invalidity of the scale-up methodology based on matching dimensionless groups [15]. Additional dimensionless groups would be required in order for hydrodynamic similarity to be attained, which make the methodology even more difficult to implement. 


\section{Conclusions}

The advanced non-invasive radioactive particle tracking (RPT) technique has been implemented to assess, for the first time, the scale-up methodology of gas-solid spouted beds based on matching dimensionless groups proposed by [15]. By measuring the radial profiles of the solids velocity, normal stresses, shear stresses, and turbulent kinetic energy, it has been found that matching the set of dimensionless groups in the studied two sizes of spouted beds did not result in the attainment of hydrodynamic similarity by comparing the values of these parameters and their dimensionless quantities. This finding confirms the findings of [14], who made local point-wise measurements of solids velocity and solids holdup using a sophisticated optical fiber probe. Also, this conclusion is consistent with the findings of [13] based on measuring the time- 
averaged cross sectional distributions solids and gas holdups and their radial profiles by implementing gamma-ray computed tomography (CT) technique. It is noteworthy that adding more dimensionless groups to capture the key phenomena, further complicates the implementation of matching dimensionless groups based scale-up methodology. The experimental data obtained in this work has two folds of industrial significance as follows:

1. The data can be used to benchmark computational fluid dynamic (CFD) and evaluate and validate the models and closures, which then can be used for simulating the industrial scale and conditions of gas-solid spouted beds.

2. The data shows that the proposed dimensionless groups for scale-up do not capture all the interplay phenomena and parameters that can be with fidelity performing scale-up for hydrodynamics similarity.

\section{Acknowledgment}

US Department of Energy - Nuclear Energy Research Initiative (DOE-NERI) grant (NERI DEFC07-07ID14822), the GAANN, chancellor fellowship, and professor Al-Dahhan's lab fund are acknowledged for the financial support that made this work possible. The second author would like to thank the King Abdulaziz City for Science and Technology (KACST) for sponsoring his Ph.D. studies at Missouri S\&T. 


\section{References}

[1] A.V. Herzog, T.E. Lipman, D.M. Kammen, Renewable energy sources, in: Encyclopedia of Life Support Systems (EOLSS). Forerunner Volume-'Perspectives and Overview of Life Support Systems and Sustainable Development, (2001).

[2] K. Sawa, S. Ueta, Research and development on HTGR fuel in the HTTR project, Nuclear Engineering and Design, 233 (2004) 163-172.

[3] C. Tang, Y. Tang, J. Zhu, Y. Zou, J. Li, X. Ni, Design and manufacture of the fuel element for the $10 \mathrm{MW}$ high temperature gas-cooled reactor, Nuclear Engineering and Design, 218 (2002) 91-102.

[4] K. Verfondern, H. Nabielek, J.M. Kendall, Coated particle fuel for high temperature gas cooled reactors, Nuclear Engineering and Technology, 39 (2007) 603. 
[5] Y.-W. Lee, J.-Y. Park, Y.K. Kim, K.C. Jeong, W.K. Kim, B.G. Kim, Y.M. Kim, M.S. Cho, Development of HTGR-coated particle fuel technology in Korea, Nuclear Engineering and Design, 238 (2008) 2842-2853.

[6] M. Liu, Y. Shao, B. Liu, Pressure analysis in the fabrication process of TRISO UO2-coated fuel particle, Nuclear Engineering and Design, 250 (2012) 277-283.

[7] I.E. Porter, T.W. Knight, M.C. Dulude, E. Roberts, J. Hobbs, Design and fabrication of an advanced TRISO fuel with ZrC coating, Nuclear Engineering and Design, 259 (2013) 180-186.

[8] G.K. Miller, D.A. Petti, J.T. Maki, D.L. Knudson, An evaluation of the effects of SiC layer thinning on failure of TRISO-coated fuel particles, Journal of Nuclear Materials, 355 (2006) $150-162$.

[9] K.B. Mathur, N. Epstein, 1 - Introduction, In Spouted Beds, Academic Press, 1974, pp. 1-13, ISBN 9780124800502.

[10] W. Shuyan, L. Yongjian, L. Yikun, W. Lixin, D. Qun, W. Chunsheng, Simulations of flow behavior of gas and particles in spouted bed with a porous draft tube, Powder Technology, 199 (2010) 238-247.

[11] T. Djeridane, F. Larachi, D. Roy, J. Chaovki, R. Legros, Investigation of the mean and turbulent particle velocity fields in a spouted bed using radioactive particle tracking, The Canadian Journal of Chemical Engineering, 76 (1998) 190-195.

[12] F.ç. Larachi, B.P.A. Grandjean, J. Chaouki, Mixing and circulation of solids in spouted beds: particle tracking and Monte Carlo emulation of the gross flow pattern, Chemical Engineering Science, 58 (2003) 1497-1507.

[13] N. Ali, T. Al-Juwaya, M. Al-Dahhana, Demonstrating the non-similarity in local holdups of gas-solid spouted beds obtained by CT with scale-up methodology based on dimensionless groups.,Chemical Engineering Research and Design, \#\# (2016) "Submitted" or "under consideration".

[14] S.B. Aradhya, Scaleup and hydrodynamics study of gas-solid spouted beds, Department of Chemical and Biochemical Engineering. Missouri University of Science and Technology, Doctoral Dissertations. (2013) Paper 2254.

[15] Y.L. He, C.J. Lim, J.R. Grace, Scale-up studies of spouted beds, Chemical Engineering Science, 52 (1997) 329-339.

[16] L.R. Glicksman, Scaling relationships for fluidized beds, Chemical Engineering Science, 39 (1984) 1373-1379.

[17] J. Xu, Y. Ji, W. Wei, X. Bao, W. Du, Scale-up relationships of spouted beds, The 12th International Conference on Fluidization, Vancouver, Canada, (2007).

[18] W. Du, J. Xu, Y. Ji, W. Wei, X. Bao, Scale-up relationships of spouted beds by solid stress analyses, Powder Technology, 192 (2009) 273-278. 
[19] P.A. Shirvanian, J.M. Calo, Hydrodynamic scaling of a rectangular spouted vessel with a draft duct, Chemical Engineering Journal, 103 (2004) 29-34.

[20] I.D.L. Rojas, Investigation of hydrodynamic scaling relationships in shallow spouted beds, PhD diss., University of Tennessee, 2011. http://trace.tennessee.edu/utk_graddiss/1098.

[21] S. Bhusarapu, M. Cassanello, M.H. Al-Dahhan, M.P. Dudukovic, S. Trujillo, T.J. O’Hern, Dynamical features of the solid motion in gas-solid risers, International Journal of Multiphase Flow, 33 (2007) 164-181.

[22] M.H. Al-Dahhan, Radioisotopes applications in industry: an overview, Atoms for Peace: an International Journal, 2 (2009) 324-337.

[23] S. Bhusarapu, M. Al-Dahhan, M.P. Dudukovic, Quantification of solids flow in a gas-solid riser: single radioactive particle tracking, Chemical Engineering Science, 59 (2004) 5381-5386.

[24] S. Bhusarapu, M.H. Al-Dahhan, M.P. Duduković, Solids flow mapping in a gas-solid riser: Mean holdup and velocity fields, Powder Technology, 163 (2006) 98-123.

[25] M. Cassanello, F. Larachi, A. Kemoun, M.H. Al-Dahhan, M.P. Dudukovic, Inferring liquid chaotic dynamics in bubble columns using CARPT, Chemical Engineering Science, 56 (2001) 6125-6134.

[26] J. Chen, A. Kemoun, M.H. Al-Dahhan, M.P. Duduković, D.J. Lee, L.-S. Fan, Comparative hydrodynamics study in a bubble column using computer-automated radioactive particle tracking (CARPT)/computed tomography (CT) and particle image velocimetry (PIV), Chemical Engineering Science, 54 (1999) 2199-2207.

[27] H.-P. Luo, A. Kemoun, M.H. Al-Dahhan, J.M.F. Sevilla, J.L.G.a. Sánchez, F.G.a. Camacho, E.M. Grima, Analysis of photobioreactors for culturing high-value microalgae and cyanobacteria via an advanced diagnostic technique: CARPT, Chemical Engineering Science, 58 (2003) 25192527.

[28] A.R. Rammohan, A. Kemoun, M.H. Al-Dahhan, M.P. Dudukovic, Characterization of Single Phase Flows in Stirred Tanks via Computer Automated Radioactive Particle Tracking (CARPT), Chemical Engineering Research and Design, 79 (2001) 831-844.

[29] A.R. Rammohan, A. Kemoun, M.H. Al-Dahhan, M.P. Dudukovic, A Lagrangian description of flows in stirred tanks via computer-automated radioactive particle tracking (CARPT), Chemical Engineering Science, 56 (2001) 2629-2639.

[30] F. Larachi, J. Chaouki, G. Kennedy, M.P. Dudukovic, Chapter 11 - Radioactive particle tracking in multiphase reactors: Principles and applications, in: J.C.L.P. Duduković (Ed.) NonInvasive Monitoring of Multiphase Flows, Elsevier Science B.V., Amsterdam, (1997), pp. 335406.

[31] D. Roy, F. Larachi, R. Legros, J. Chaouki, A study of solid behavior in spouted beds using 3-D particle tracking, The Canadian Journal of Chemical Engineering, 72 (1994) 945-952. 
[32] R.K. Upadhyay, S. Roy, Investigation of hydrodynamics of binary fluidized beds via radioactive particle tracking and dual-source densitometry, The Canadian Journal of Chemical Engineering, 88 (2010) 601-610.

[33] M.S. Vesvikar, M. Al-Dahhan, Hydrodynamics investigation of laboratory-scale Internal Gas-lift loop anaerobic digester using non-invasive CAPRT technique, Biomass and Bioenergy, 84 (2016) 98-106.

[34] S. Roy, F. Larachi, M.H. Al-Dahhan, M.P. Duduković, Optimal design of radioactive particle tracking experiments for flow mapping in opaque multiphase reactors, Applied Radiation and Isotopes, 56 (2002) 485-503.

[35] V.B. Khane, Experimental and computational investigation of flow of pebbles in a pebble bed nuclear reactor, Department of Chemical and Biochemical Engineering, Missouri University of Science and Technology, Rolla, Missouri, Doctoral Dissertations, (2014).

[36] M.K.A. Mesfer, Effect of Dense Heat Exchanging Internals on the Hydrodynamics of Bubble Column Reactors Using Non-invasive Measurement Techniques, Department of Chemical and Biochemical Engineering, Missouri University of Science and Technology, Rolla, Missouri, Doctoral Dissertations, (2013).

[37] K.B. Mathur, P.E. Gishler, A technique for contacting gases with coarse solid particles, AIChE Journal, 1 (1955) 157-164.

\section{Notation}

$d_{p} \quad$ particle diameter, $\mathrm{m}$

$D_{c} \quad$ inner column diameter, $\mathrm{m}$

$D_{i} \quad$ inlet orifice diameter, $\mathrm{m}$

$e_{s s} \quad$ restitution coefficient of the particles

$\mathrm{Fr} \quad$ Froude number

$g$ acceleration of gravity, $\mathrm{m} \mathrm{s}^{-2}$

$H \quad$ static bed height, $\mathrm{m}$

$H_{F} \quad$ fountain height, $\mathrm{m}$

$H_{m} \quad$ maximum spoutable bed depth, $\mathrm{m}$

L column length, $\mathrm{m}$

$N_{v} \quad$ total number of occurrences per compartment. 
$\tilde{N}_{v} \quad$ the average number of velocity occurrences for a given two-dimensional compartment (i, k).

$\mathrm{Nr} \quad$ number of radial positions for column discretization.

$N_{\theta} \quad$ number of azimuthal positions for column discretization.

$P \quad$ bed pressure, $\mathrm{Pa}$

Re Reynolds number

$R \quad$ column radius, $\mathrm{cm}$

$T \quad$ bed temperature, $\mathrm{K}$

$\mathrm{T}$ time, second

TKE turbulent kinetic energy (per unit bulk density), $\mathrm{cm}^{2} \mathrm{~s}^{-2}$

$U \quad$ superficial gas velocity, $\mathrm{m} \mathrm{s}^{-1}$

$U_{m s} \quad$ minimums pouting velocity, $\mathrm{m} \mathrm{s}^{-1}$

$\mathrm{U} \quad$ axially averaged of the mean particle velocity $(\bar{u}), \mathrm{m} \mathrm{s}^{-1}$

$u \quad$ instantaneous local particle velocity, $\mathrm{cm} / \mathrm{s}$

$\bar{u} \quad$ averaged particle velocity, $\mathrm{cm} / \mathrm{s}$

$u^{\prime} \quad$ fluctuating particle velocity, $\mathrm{cm} / \mathrm{s}$

$\mathrm{z} \quad$ axial distance form inlet orifice, $\mathrm{m}$

\section{Greek letters}

$\beta \quad$ fluid-particle interaction coefficient, $\mathrm{kg} \mathrm{m}^{3} \mathrm{~s}^{-1}$.

$\rho_{s} \quad$ particle density, $\mathrm{Kg} \mathrm{m}^{-3}$.

$\rho_{f} \quad$ fluid density, $\mathrm{Kg} \mathrm{m}^{-3}$.

$\mu \quad$ fluid viscosity, $\mathrm{Kg} \mathrm{m}^{-1} \mathrm{~s}^{-1}$.

$\phi_{s} \quad$ sphericity of particles.

$\varphi \quad$ inertial friction angle of particle, deg.

$\varepsilon_{m f} \quad$ bed voidage at minimum fluidization.

$\varepsilon_{o} \quad$ voidage at packed bed state

$\varepsilon_{s} \quad$ solids fraction (or solids holdup).

$\varepsilon_{g} \quad$ gas fraction (or gas holdup).

$\tau_{p q} \quad$ stress in the pq direction $(\mathrm{p}, \mathrm{q}=\mathrm{r}, \theta, \mathrm{z}), \mathrm{cm}^{2} / \mathrm{s}^{2}$. 


\section{Subscripts}

' Dimensionless parameter.

\section{List of Tables}

Table 1. Experimental conditions (Dimensions, particle properties, and scaling parameters) for matched and mismatched dimensionless groups; used for the scale-up of spouted beds [15].

Table 2. Percentage differences in shear stresses among the studied conditions of Cases A, B, and $\mathrm{C}$. 


\section{List of figures}

Fig. 1. Schematic diagram of spouted beds.

Fig. 2. Schematic diagram of the $0.076 \mathrm{~m}$ and $0.152 \mathrm{~m}$ spouted beds.

Fig. 3. Schematic diagram showing the positions of 14-detecors arranged around the 0.152 m spouted bed.

Fig. 4. Azimuthally and axially averaged radial profiles of the axial particle velocity for the conditions of the reference Case (Case A), the case with matched dimensionless groups (Case B), and the case with mismatched dimensionless groups (Case $\mathrm{C}$ ) for $0.152 \mathrm{~m}$ and $0.076 \mathrm{~m}$ spouted beds in the spout/annulus and the fountain regions.

Fig. 5. Azimuthally and axially averaged radial profiles of the dimensionless axial particle velocity for the conditions of matched and mismatched dimensionless groups for $0.152 \mathrm{~m}$ and $0.076 \mathrm{~m}$ spouted beds in the spout/annulus and the fountain regions $\left(\mathrm{U}_{\mathrm{ms}}=89,61,68 \mathrm{~cm} / \mathrm{s}\right.$, respectively for Cases A, B, and C). 
Fig. 6. Azimuthally and axially averaged radial profiles of the radial particle velocity for the conditions of matched and mismatched dimensionless groups for $0.152 \mathrm{~m}$ and $0.076 \mathrm{~m}$ spouted beds in the spout/annulus and the fountain regions.

Fig. 7. Azimuthally and axially averaged radial profiles of the dimensionless radial particle velocity for the conditions of matched and mismatched dimensionless groups for $0.152 \mathrm{~m}$ and $0.076 \mathrm{~m}$ spouted beds in the spout/annulus and the fountain regions $\left(\mathrm{U}_{\mathrm{ms}}=89,61,68 \mathrm{~cm} / \mathrm{s}\right.$, respectively for Cases $\mathrm{A}, \mathrm{B}$, and $\mathrm{C}$ ).

Fig. 8. Azimuthally and axially averaged radial profiles of (a) the axial normal stresses and (b) the dimensionless axial normal stresses with respect to the squared minimum spouting velocity, in the spout/annulus and the fountain regions for the conditions of matched and mismatched dimensionless groups for $0.152 \mathrm{~m}$ and $0.076 \mathrm{~m}$ spouted beds $\left(\mathrm{U}_{\mathrm{ms}}=89,61\right.$, and 68 $\mathrm{cm} / \mathrm{s}$, respectively for Case A, B, and C).

Fig. 9. Azimuthally and axially averaged radial profiles of the radial normal stresses in (a) and (b) the dimensionless radial normal stress, in the spout/annulus and (d) the fountain regions for the conditions of matched and mismatched dimensionless groups for $0.152 \mathrm{~m}$ and $0.076 \mathrm{~m}$ spouted beds $\left(\mathrm{U}_{\mathrm{ms}}=89,61\right.$, and $68 \mathrm{~cm} / \mathrm{s}$, respectively for Case $\mathrm{A}, \mathrm{B}$, and $\left.\mathrm{C}\right)$.

Fig. 10. Azimuthally and axially averaged radial profiles of (a) the azimuthal normal stresses, and (b) the dimensionless azimuthal normal stresses, in the spout/annulus and the fountain regions for the conditions of matched and mismatched dimensionless groups for 0.152 $\mathrm{m}$ and $0.076 \mathrm{~m}$ spouted beds $\left(\mathrm{U}_{\mathrm{ms}}=89,61\right.$, and $68 \mathrm{~cm} / \mathrm{s}$, respectively for Case $\mathrm{A}, \mathrm{B}$, and $\left.\mathrm{C}\right)$.

Fig. 11. Azimuthally and axially averaged radial profiles of the shear stresses for the conditions of matched and mismatched dimensionless groups for $0.152 \mathrm{~m}$ and $0.076 \mathrm{~m}$ spouted beds in the spout/annulus and the fountain regions.

Fig. 12. Azimuthally and axially averaged radial profiles of the dimensionless shear stresses in the spout/annulus and the fountain regions for the conditions of matched and mismatched dimensionless groups for $0.152 \mathrm{~m}$ and $0.076 \mathrm{~m}$ spouted beds $\left(U_{\mathrm{ms}}=89,61\right.$, and $68 \mathrm{~cm} / \mathrm{s}$, respectively for Case $\mathrm{A}, \mathrm{B}$, and $\mathrm{C}$ ).

Fig. 13. Azimuthally and axially averaged radial profiles of turbulent kinetic energy (per unit bulk density), And (b) the dimensionless turbulent kinetic energy, in the spout/annulus and the fountain regions for the conditions of matched and mismatched dimensionless groups for $0.152 \mathrm{~m}$ and $0.076 \mathrm{~m}$ spouted beds $\left(\mathrm{U}_{\mathrm{ms}}=89,61\right.$, and $68 \mathrm{~cm} / \mathrm{s}$, respectively for Case $\mathrm{A}$, B, and C). 
Table 1. Experimental conditions (Dimensions, particle properties, and scaling parameters) for matched and mismatched dimensionless groups; used for the scale-up of spouted beds [15].

\begin{tabular}{|c|c|c|c|}
\hline Condition/Case & A & B & C \\
\hline$D_{c}(m)$ & 0.152 & 0.076 & 0.076 \\
\hline$D_{i}(\mathrm{~mm})$ & 19.1 & 9.5 & 9.5 \\
\hline$L(m)$ & 1.14 & 1.14 & 1.14 \\
\hline$H(m)$ & 0.323 & 0.16 & 0.16 \\
\hline$T(K)$ & 298 & 298 & 298 \\
\hline$P(k P a)$ & 101 & 312 & 101 \\
\hline Particles & Glass & Steel & Glass \\
\hline$d_{p}(m m)$ & 2.18 & 1.09 & 1.09 \\
\hline$\rho_{s}\left(\mathrm{~kg} / \mathrm{m}^{3}\right)$ & 2400 & 7400 & 2450 \\
\hline$\rho_{f}\left(\mathrm{~kg} / \mathrm{m}^{3}\right)$ & 1.21 & 3.71 & 1.21 \\
\hline$\mu\left(x 10^{\wedge} 5\right)($ Pa.s $)$ & 1.81 & 1.81 & 1.81 \\
\hline$U(\mathrm{~m} / \mathrm{s})$ & 1.08 & 0.75 & 0.74 \\
\hline
\end{tabular}




\begin{tabular}{|c|c|c|c|}
\hline$U_{m s}($ measured, $\mathrm{m} / \mathrm{s})$ & 0.89 & 0.61 & 0.68 \\
\hline \multicolumn{4}{|l|}{ Scaling groups } \\
\hline$\phi_{s}$ & 1 & 1 & 1 \\
\hline$\varphi\left(^{\circ}\right)$ & 26 & 28 & 27 \\
\hline$\varepsilon_{m f}$ & 0.41 & 0.42 & 0.42 \\
\hline$H / D_{c}$ & 2.1 & 2.1 & 2.1 \\
\hline$D_{c} / D_{i}$ & 8 & 8 & 8 \\
\hline$D_{c} / d_{p}$ & 70 & 70 & 70 \\
\hline$\rho_{s} / \rho_{f}$ & 1994 & 1995 & 2029 \\
\hline$R e=\rho_{f} d_{p} U / \mu$ & 157 & 168 & 54 \\
\hline$F r=U^{2} / g d_{p}$ & 54.5 & 52.6 & 51.2 \\
\hline$\rho_{s} d_{p} U / \mu\left(x 10^{-3}\right)$ & 313 & 334 & 109 \\
\hline$U^{2} / g D_{c}$ & 0.78 & 0.75 & 0.73 \\
\hline
\end{tabular}

Table 2. Percentage differences in shear stresses among the studied conditions of Cases A, $\mathrm{B}$, and $\mathrm{C}$.

\begin{tabular}{|c|c|c|c|c|c|c|c|}
\hline Dimensionless shear stress & $\tau_{\mathrm{rz}}^{\prime}$ & $\tau_{\mathrm{z} \theta^{\prime}}$ & $\tau_{\mathrm{r} \theta^{\prime}}$ & $\tau_{\mathrm{rz}}{ }^{\prime}$ & $\tau_{\mathrm{z} \theta^{\prime}}$ & $\tau_{\mathrm{r}{ }^{\prime}}$ \\
\hline & \multicolumn{2}{|c|}{ Deviation (\%) in spout } & \multicolumn{2}{|c|}{ Deviation (\%) in fountain } \\
\hline Case A & - & - & - & - & - & - \\
\hline Case B & 62.03 & 54.71 & 47.56 & 52.96 & 40.2 & 57.76 \\
\hline Case C & 69.98 & 58.02 & 58.31 & 40.17 & 48.74 & 41.19 \\
\hline
\end{tabular}




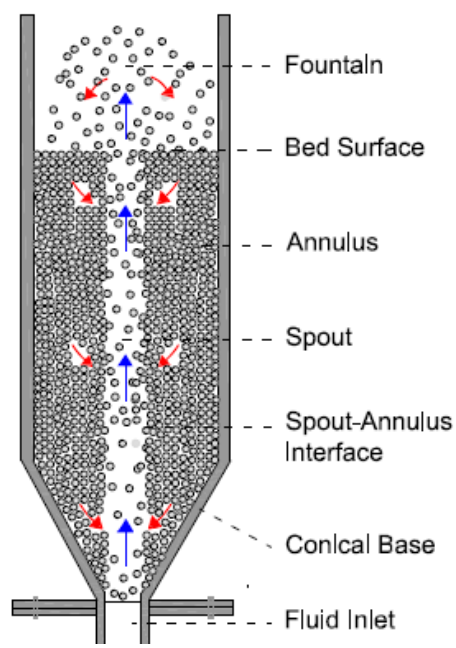

Fig. 1. Schematic diagram of spouted beds. 


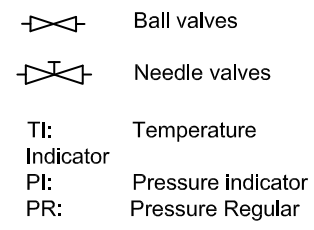

(PI)
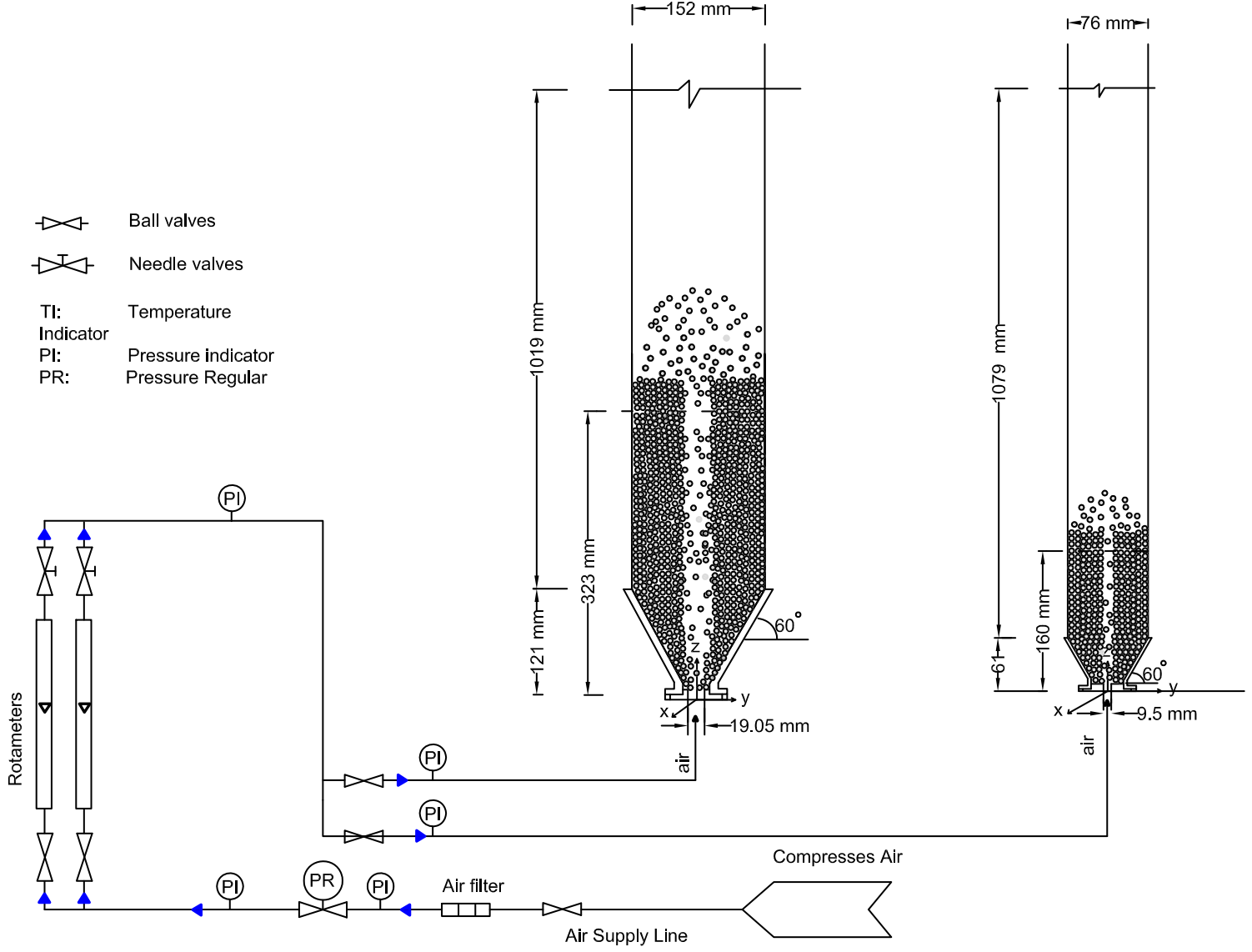

Fig. 2. Schematic diagram of the $0.076 \mathrm{~m}$ and $0.152 \mathrm{~m}$ spouted beds. 


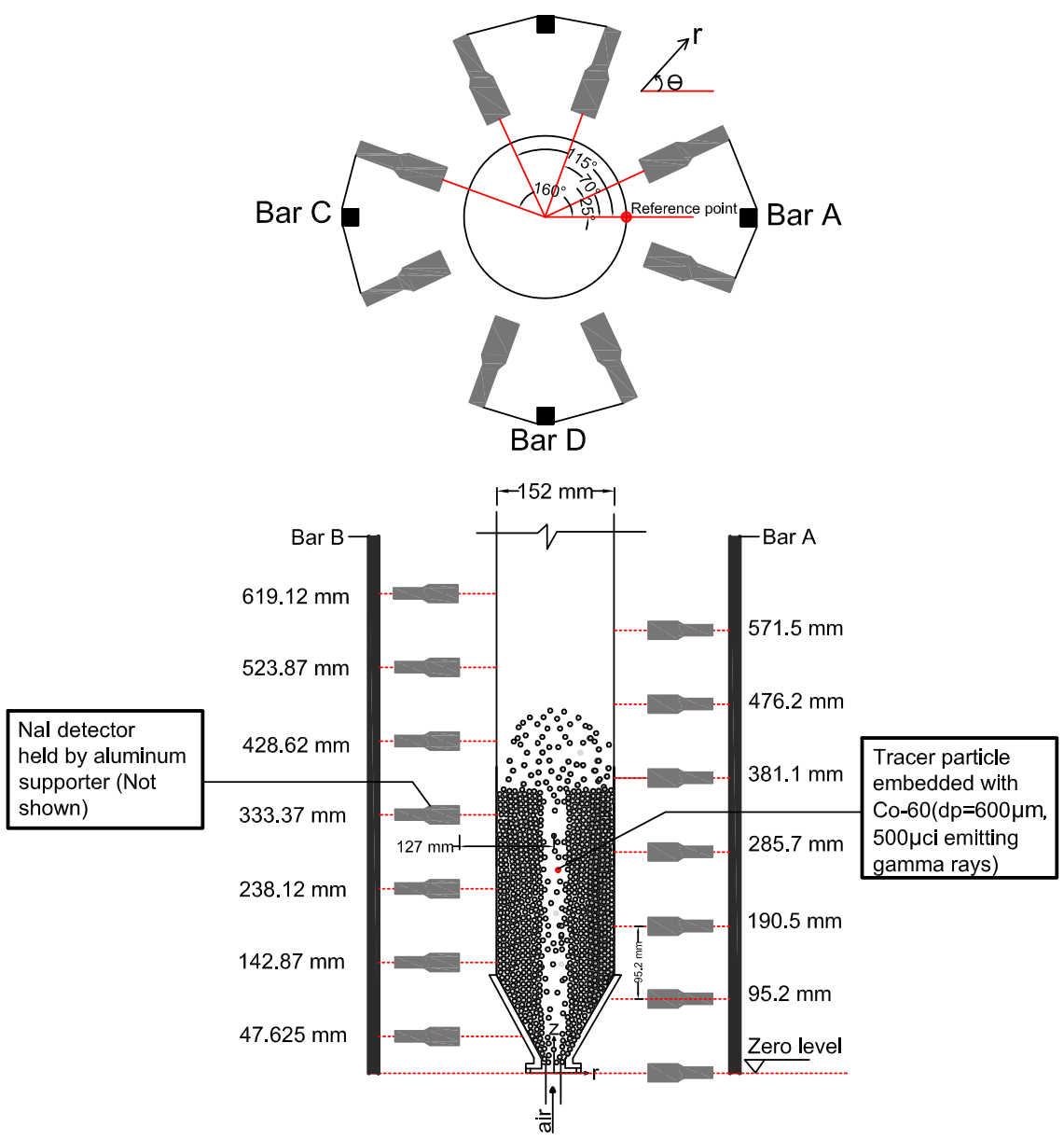

Fig. 3. Schematic diagram showing the positions of 14-detecors arranged around the 0.152 m spouted bed. 


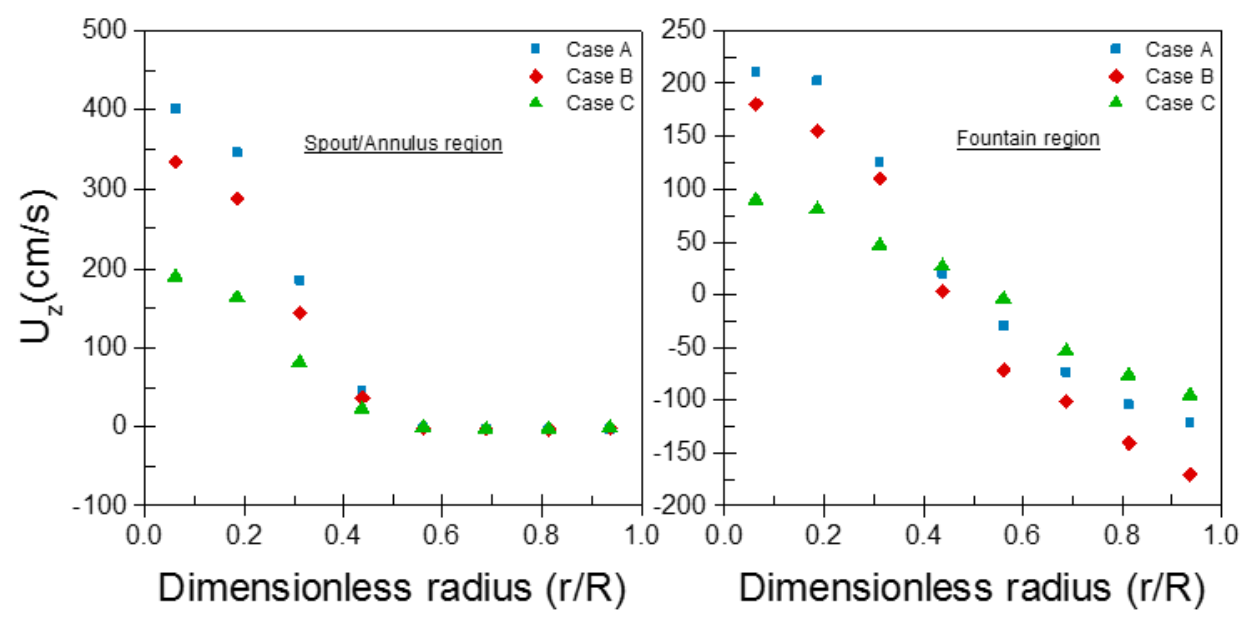

Fig. 4. Azimuthally and axially averaged radial profiles of the axial particle velocity for the conditions of the reference Case (Case A), the case with matched dimensionless groups (Case B), and the case with mismatched dimensionless groups (Case $\mathrm{C}$ ) for $0.152 \mathrm{~m}$ and $0.076 \mathrm{~m}$ spouted beds in the spout/annulus and the fountain regions. 

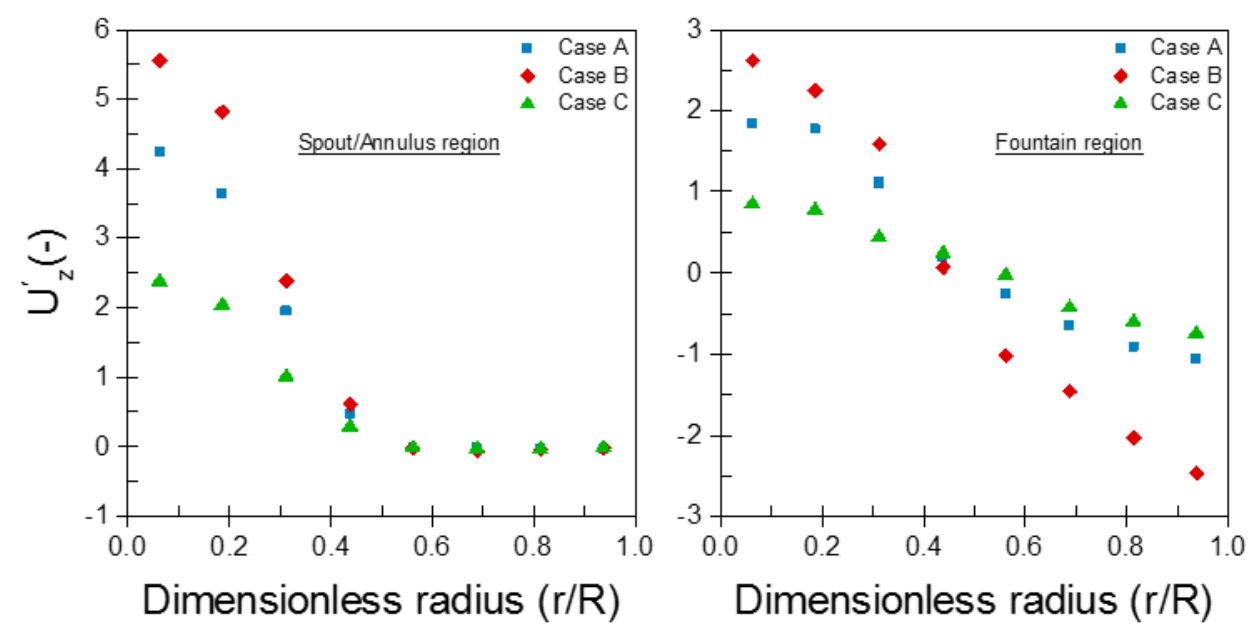

Fig. 5. Azimuthally and axially averaged radial profiles of the dimensionless axial particle velocity for the conditions of matched and mismatched dimensionless groups for $0.152 \mathrm{~m}$ and $0.076 \mathrm{~m}$ spouted beds in the spout/annulus and the fountain regions $\left(\mathrm{U}_{\mathrm{ms}}=89,61,68 \mathrm{~cm} / \mathrm{s}\right.$, respectively for Cases $\mathrm{A}, \mathrm{B}$, and $\mathrm{C}$ ). 

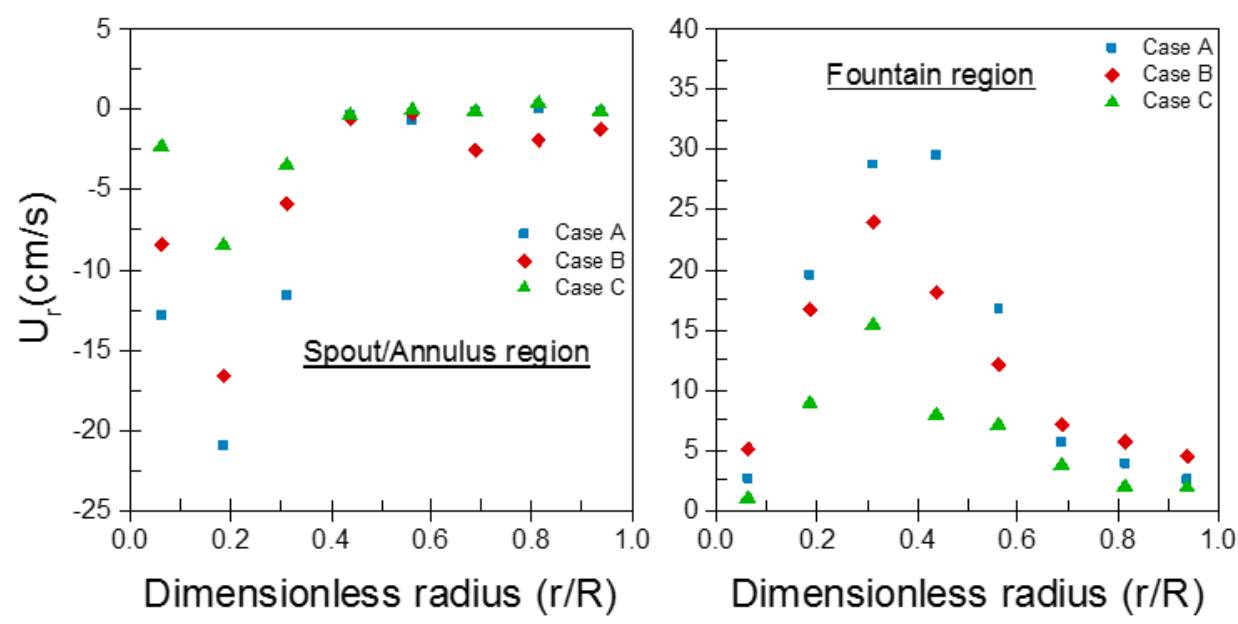

Fig. 6. Azimuthally and axially averaged radial profiles of the radial particle velocity for the conditions of matched and mismatched dimensionless groups for $0.152 \mathrm{~m}$ and $0.076 \mathrm{~m}$ spouted beds in the spout/annulus and the fountain regions. 


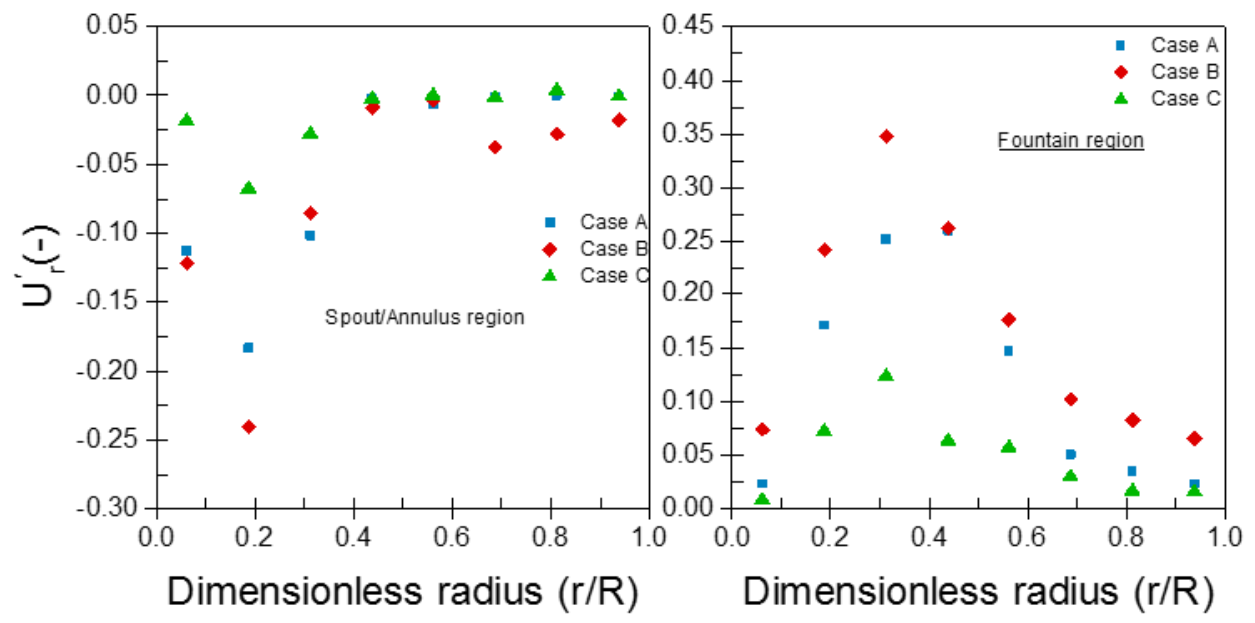

Fig. 7. Azimuthally and axially averaged radial profiles of the dimensionless radial particle velocity for the conditions of matched and mismatched dimensionless groups for $0.152 \mathrm{~m}$ and $0.076 \mathrm{~m}$ spouted beds in the spout/annulus and the fountain regions $\left(\mathrm{U}_{\mathrm{ms}}=89,61,68 \mathrm{~cm} / \mathrm{s}\right.$, respectively for Cases $\mathrm{A}, \mathrm{B}$, and $\mathrm{C}$ ). 
(a)
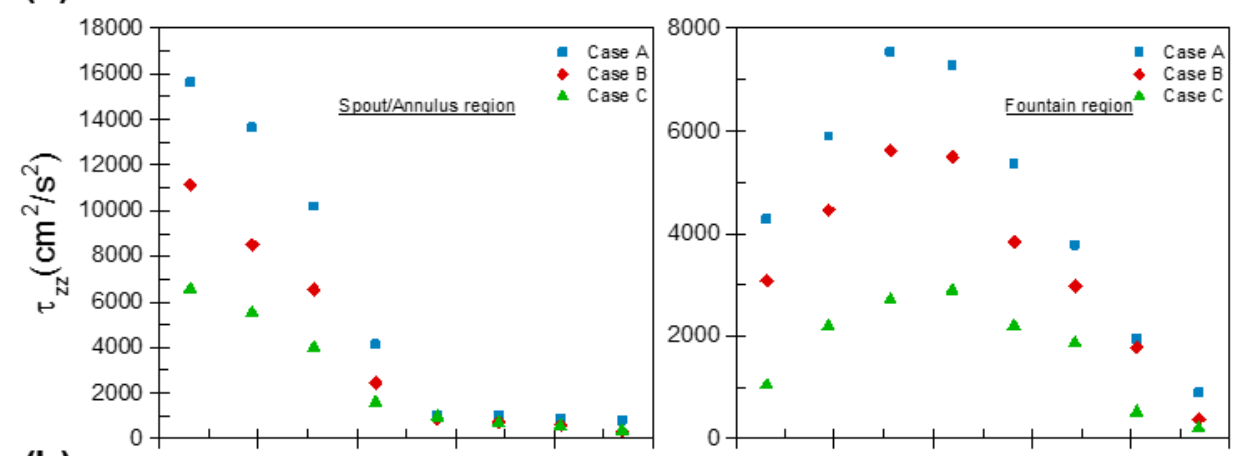

(b)
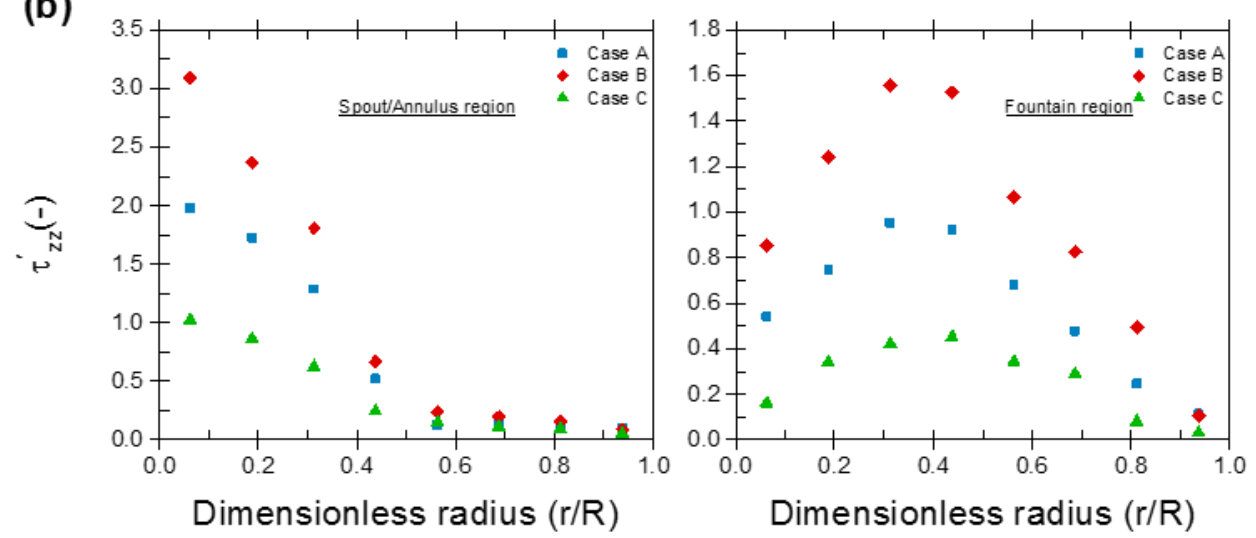

Fig. 8. Azimuthally and axially averaged radial profiles of (a) the axial normal stresses and (b) the dimensionless axial normal stresses with respect to the squared minimum spouting velocity, in the spout/annulus and the fountain regions for the conditions of matched and mismatched dimensionless groups for $0.152 \mathrm{~m}$ and $0.076 \mathrm{~m}$ spouted beds $\left(\mathrm{U}_{\mathrm{ms}}=89,61\right.$, and 68 $\mathrm{cm} / \mathrm{s}$, respectively for Case A, B, and C). 

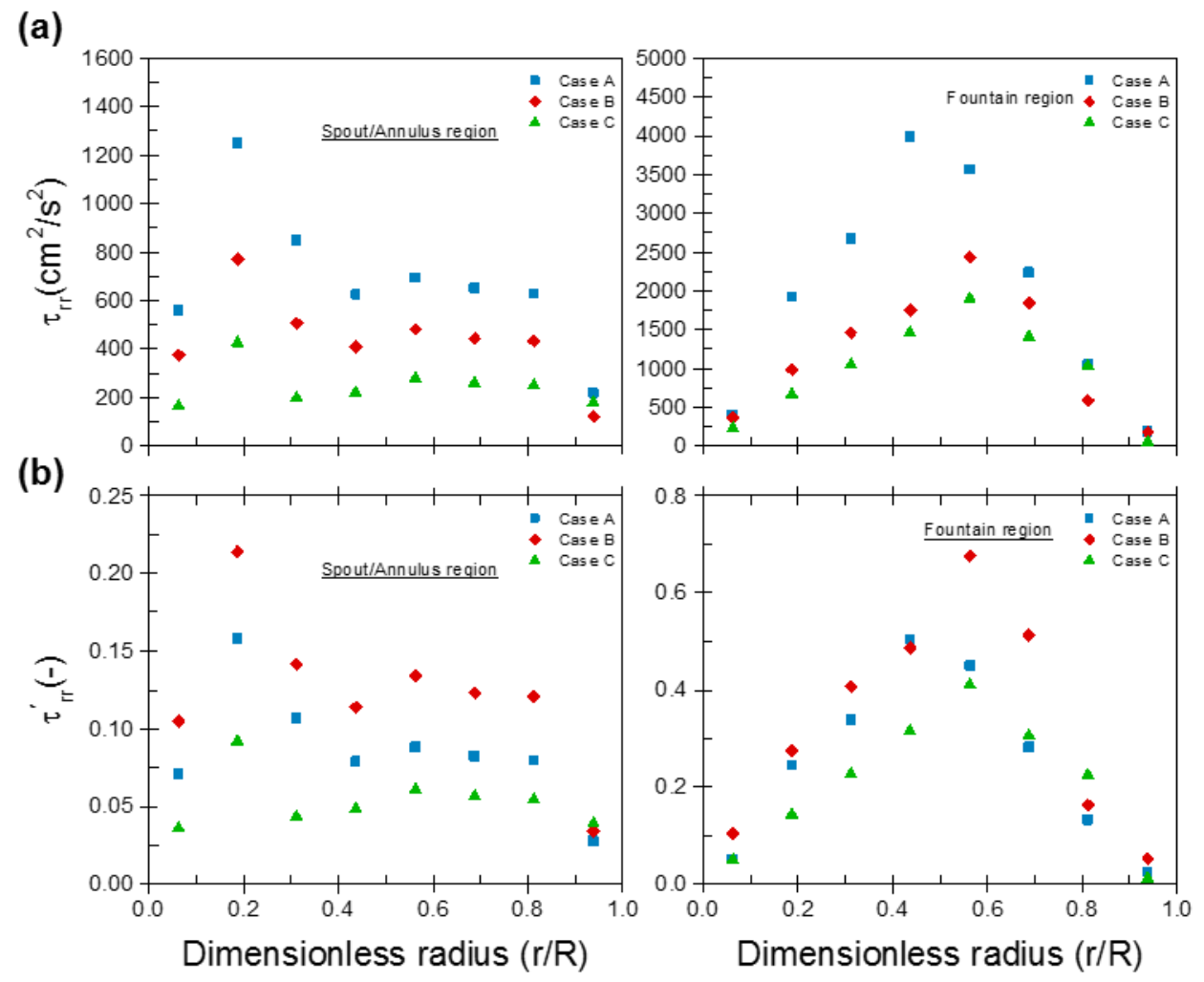

Fig. 9. Azimuthally and axially averaged radial profiles of the radial normal stresses in (a) and (b) the dimensionless radial normal stress, in the spout/annulus and (d) the fountain regions for the conditions of matched and mismatched dimensionless groups for $0.152 \mathrm{~m}$ and 0.076 spouted beds $\left(\mathrm{U}_{\mathrm{ms}}=89,61\right.$, and $68 \mathrm{~cm} / \mathrm{s}$, respectively for Case $\mathrm{A}, \mathrm{B}$, and $\mathrm{C}$ ). 

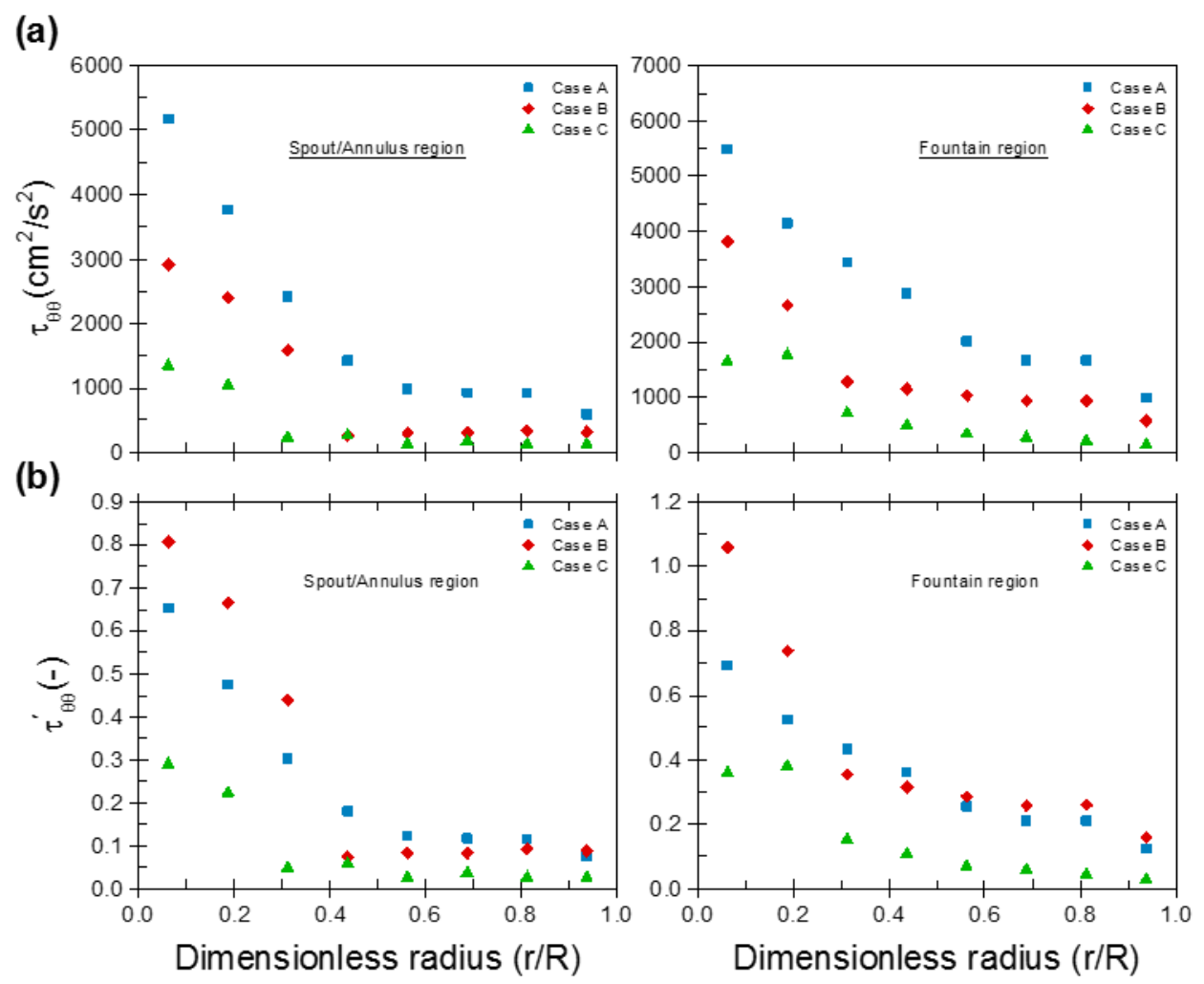

Fig. 10. Azimuthally and axially averaged radial profiles of (a) the azimuthal normal stresses, and (b) the dimensionless azimuthal normal stresses, in the spout/annulus and the fountain regions for the conditions of matched and mismatched dimensionless groups for 0.152 $\mathrm{m}$ and $0.076 \mathrm{~m}$ spouted beds $\left(\mathrm{U}_{\mathrm{ms}}=89,61\right.$, and $68 \mathrm{~cm} / \mathrm{s}$, respectively for Case $\mathrm{A}, \mathrm{B}$, and $\left.\mathrm{C}\right)$. 

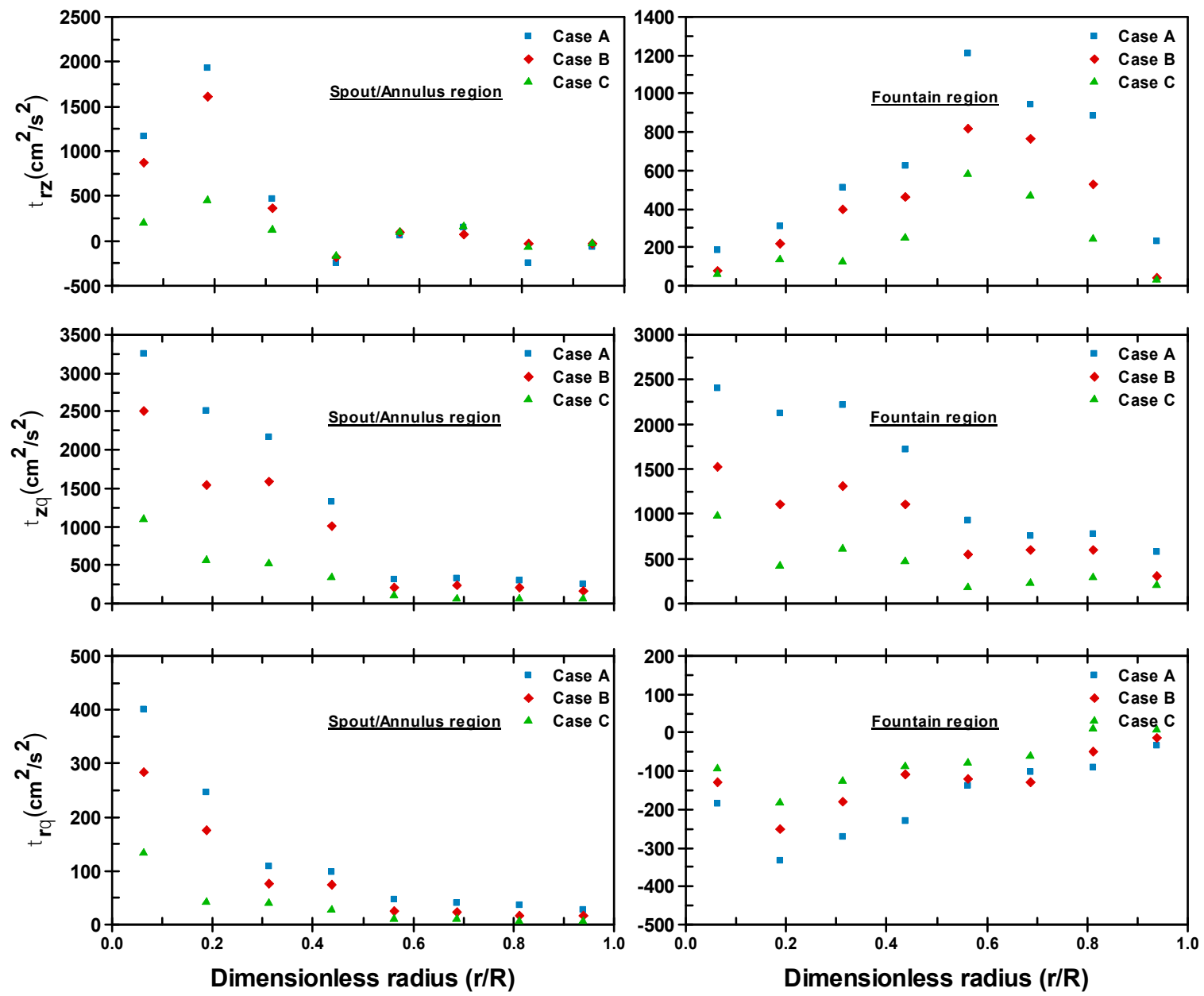

Fig. 11. Azimuthally and axially averaged radial profiles of the shear stresses for the conditions of matched and mismatched dimensionless groups for $0.152 \mathrm{~m}$ and $0.076 \mathrm{~m}$ spouted beds in the spout/annulus and the fountain regions. 

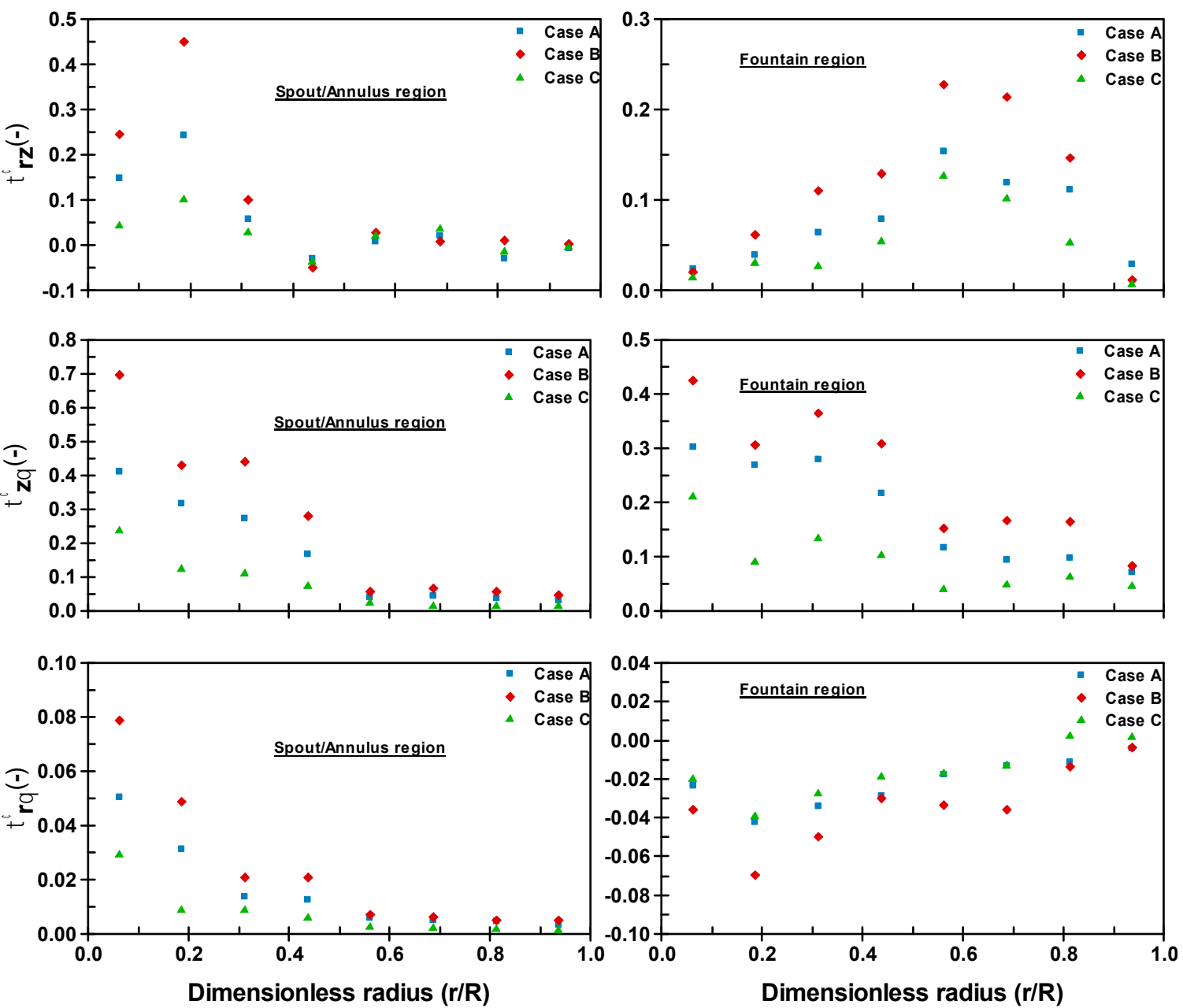

Fig. 12. Azimuthally and axially averaged radial profiles of the dimensionless shear stresses in the spout/annulus and the fountain regions for the conditions of matched and mismatched dimensionless groups for $0.152 \mathrm{~m}$ and $0.076 \mathrm{~m}$ spouted beds $\left(\mathrm{U}_{\mathrm{ms}}=89,61\right.$, and $68 \mathrm{~cm} / \mathrm{s}$, respectively for Case $\mathrm{A}, \mathrm{B}$, and $\mathrm{C}$ ). 
(a)

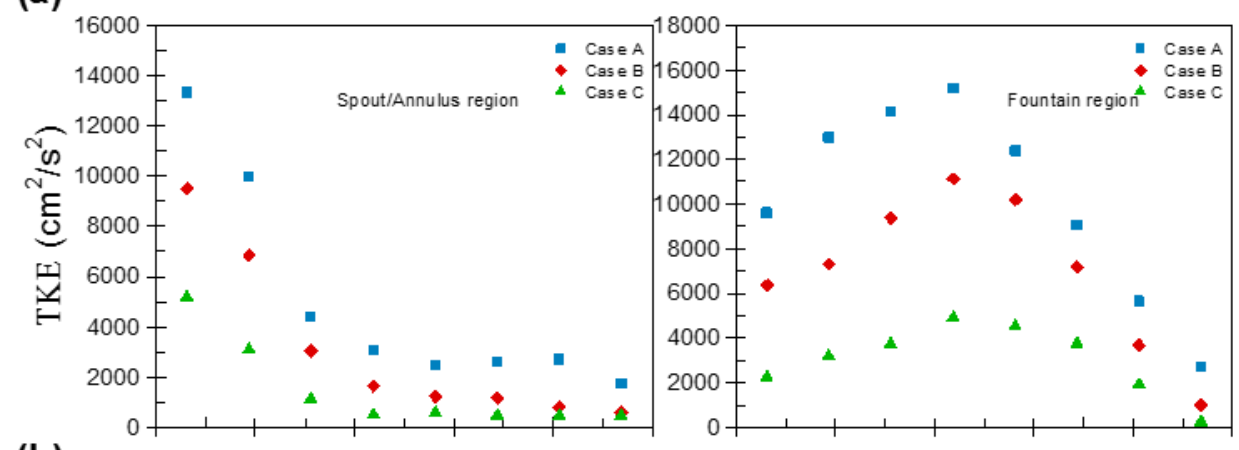

(b)
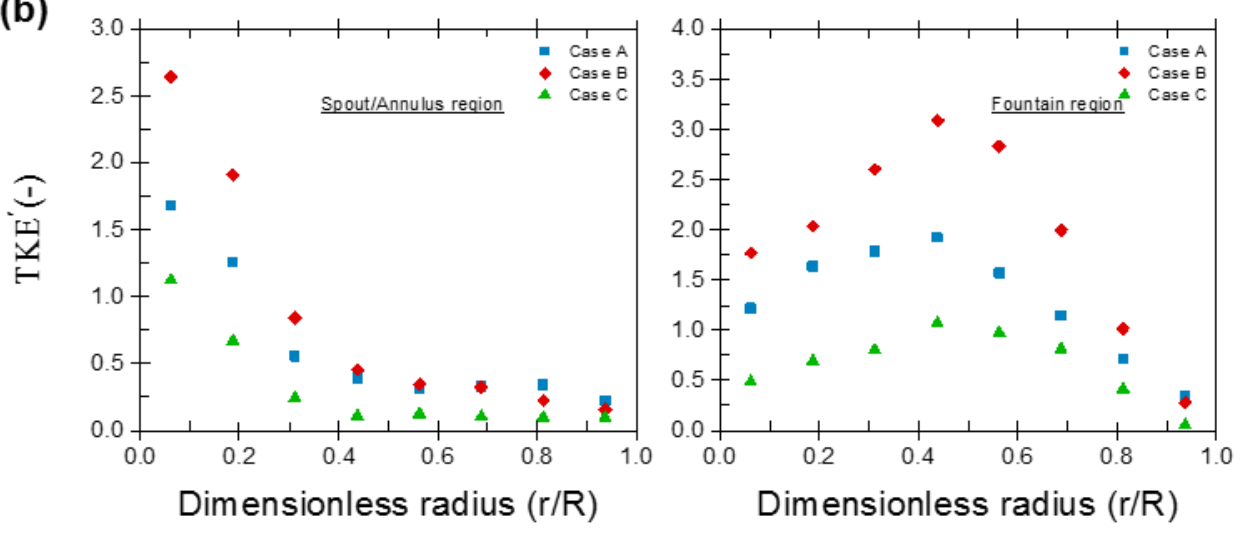

Fig. 13. Azimuthally and axially averaged radial profiles of turbulent kinetic energy (per unit bulk density), And (b) the dimensionless turbulent kinetic energy, in the spout/annulus and the fountain regions for the conditions of matched and mismatched dimensionless groups for $0.152 \mathrm{~m}$ and $0.076 \mathrm{~m}$ spouted beds $\left(\mathrm{U}_{\mathrm{ms}}=89,61\right.$, and $68 \mathrm{~cm} / \mathrm{s}$, respectively for Case $\mathrm{A}, \mathrm{B}$, and C). 